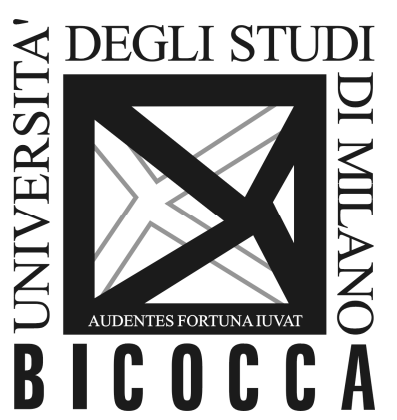

\author{
DEPARTMENT OF ECONOMICS, \\ MANAGEMENT AND STATISTICS \\ UNIVERSITY OF MILAN - BICOCCA
}

DEMS WORKING PAPER SERIES



Dipartimento di Economia, Metodi Quantitativi e Strategie di Impresa Università degli Studi di Milano - Bicocca

http://dems.unimib.it/ 


\title{
Long-run Unemployment and Macroeconomic Volatility
}

\author{
Stefano Fasani* \\ University of Milan Bicocca \\ October 10, 2016 \\ First draft - April 2016
}

\begin{abstract}
This paper develops a DSGE model with downward nominal wage rigidity, in which aggregate price and productivity dynamics are exogenously determined by independent Brownian motions with drift. As a result, the long-run expected value of unemployment depends positively on the drift coefficients and negatively on the volatility coefficients of both price and productivity growth processes. Model prescriptions are empirically tested by using a dataset including a wide sample of OECD countries from a period spanning from 1961 to 2011. Panel regressions with fixed effects and time dummies confirm the expected relation of inflation and productivity with unemployment at low frequencies. Long-run unemployment is negatively correlated with the levels of inflation and productivity growth, and positively with their volatilities.
\end{abstract}

Keywords: Long-run unemployment, Downward Nominal Wage Rigidity, Volatility, Inflation targeting, DSGE model, Cross-country panel data.

JEL codes: E12, E24, E31, C23

\footnotetext{
*Post-doc fellow at Dipartimento di Economia, Metodi Quantitativi e Strategie di Impresa, University of Milan Bicocca, Piazza dell'Ateneo Nuovo 1, 20126 Milan, Italy; PhD candidate at Deparment of Economics and Finance, University of Rome Tor Vergata, via Columbia 2, 00133 Rome, Italy. Email: stefano.fasani@unimib.it. I am very grateful for helpful comments and discussions to Pierpaolo Benigno, Giovanna Vallanti, Paolo Surico, Paolo Paesani, Tommaso Proietti, Lorenza Rossi, along with seminar participants at Phd Economics and Finance Seminars at University of Tor Vergata, and at $4^{\text {th }}$ Workshop in Macro Banking and Finance organized by the University of Rome Sapienza and Unicredit \& Univesities Foundation.
} 


\section{Introduction}

One of the fundamental of the Neoclassical Synthesis is the dichotomy between monetary policy and real aggregate variables in the long-run. According to the Synthesis, variations of nominal variables might have real effects only in the short-run, when adjustments in the economy are prevented by different types of rigidity. When in the long-run these rigidities vanish, both prices and wages are free to fluctuate, thereby employment and output converge to their natural levels. The relation between real variables and inflation becomes so vertical and the monetary policy loses its potential effectiveness. But the reality of the last decades, at least in the developed countries, has said something different. Rigidities in nominal wages adjustments have shown some persistence in vanishing, and policymakers have regularly managed the fluctuations of real variables, pursuing a positive target on inflation. The Classical Dichotomy has been then challenged in the literature by several contributions, which conversely aim to show how the dynamics between real and nominal sides of the economy are not necessary independent in the long-run. Starting with Tobin (1972), and then with Akerlof et al. $(1996,2000)$, different papers have stressed on the long-run negative relation between inflation and unemployment, that is on a non-vertical long-run Phillips curve. ${ }^{1}$ This paper contributes to this literature exploring the relationship at low frequencies, between unemployment and the dynamics of the nominal and the real processes of the economy. Importantly, this paper wishes to investigate not only on the relation between unemployment and the first moments of price and productivity growth, but also on their second moments, whose contribution has been less discussed so far. Such relations are firstly studied in the theory, through a dynamic stochastic general equilibrium model featured by i) downward rigidity of nominal wages and ii) exogenous processes with drift for prices and productivity. The main result of the theoretical model is a long-run Phillips curve in closed-form, which relates expected unemployment with the first and the second moments of inflation and productivity growth. This long-run relationship disentangles the effects of the levels of inflation and productivity growth from the effects of the volatilities of the same processes. Unemployment results to be negatively related to the levels of price and productivity growth, and positively to their volatilities. The economic intuition is that the labor margin, and then the spell of unemployed workers, have to compensate whenever downward rigidities prevent nominal wages from fluctuating freely. In the short-run horizon, the less the nominal wages have to decrease in response to business cycle fluctuations, the less downward rigidities have to bind, and the fewer are the cases in which labor input misses the full employment level, or equally,

\footnotetext{
${ }^{1}$ On the non-neutrality of monetary policy in the long-run, important references are Fisher and Seater (1993), King and Watson (1994), Fair (2000). Ball (1997, 1999) argues that the natural unemployment rate increased among the OECD countries during disinflationary periods. More recently, Svensson (2015) investigates on the long-run unemployment costs due to the undershooting of inflation target.
} 
unemployment has to increase above its natural level. In the long-run horizon, this means that the less the nominal wage dynamics is constrained by downward rigidities, the lower is the expected value of unemployment rate. Higher drifts and lower volatilities of price and productivity growth make nominal wage dynamics less affected by downward rigidities. Hence, the negative relation of expected unemployment with drifts of price and productivity growth is explained by the fact that these drifts foster, ceteris paribus, the level of nominal wages, making them less exposed to negative realizations of nominal and real shocks. The positive relation of unemployment with the volatilities of price and productivity growth is instead explained by the influence of their to the variability of nominal wages. For any given trend, a higher volatility in either nominal or real process implies that nominal wages have to adjust more frequently and then on average, have to face more often downward rigidities. The theoretical prescriptions of the model are tested empirically in the second part of the paper. Panel data are used to provide a cross-country analysis aimed to capture the international evidence on the associations at low frequencies between unemployment and the moments of price and productivity process. A linear version of the long-run Phillips curve derived in the theory, is estimated using observations collected for a sample of 33 members of OECD countries for the period spanning from 1961 to 2011. In panel regressions, unemployment mean is the endogenous variable, whereas mean and standard deviation of both inflation and productivity growth are the regressors. ${ }^{2}$ Estimation results support the implications of the theory, suggesting that at low frequencies, unemployment is negatively related to the levels of price and productivity growth, whereas it is positively related to their volatilities. Remarkably, these results are robust not only by using different measures of inflation and productivity, but also when the empirical model keeps track of the degree of rigidity of the countries. In those countries in which downward rigidities are less likely to bind, because of high values of price inflation, the relations provided by the long-run of Phillips curve are weaker. As an implication, expected unemployment in the long-run is effectively endogenously determined by the first two moments of the processes that lead the nominal growth of the economy, when downward nominal wage rigidities are binding.

Both the assumptions of nominal wage rigidities and non-stationary processes for price level are however widely discussed in the literature. Regarding the nominal wage downward rigidity, many contributions, both at micro and macro level, conclude that nominal wages adjust more easily upwardly than downwardly. In the micro literature, the wage rigidity is documented using data not only at firm- and industrial-level, ${ }^{3}$ but

\footnotetext{
${ }^{2}$ Since the empirical analysis focuses on the long-run, to extrapolate the moments at low-frequencies of the series, the full interval of time is divided into 10-year rolling windows. For each window, it is calculated the average and the standard deviation of the variable of interest. The series of averages and standard deviations are then used in the regressions. Any observation in the series corresponds to the average or the standard deviation of the variables for the previous 10 years.

${ }^{3}$ Some examples dealing with US firms data are Akerlof et al. (1996), Kahn (1997), Card and
} 
also on survey basis. ${ }^{4}$ Using survey-based data on US firms indeed, Bewley (1999) explains the downward stickiness of nominal wages, contrasting the common view that rigidities come from the reluctance of workers in accepting wage cuts. His survey indicates that the firms are scarcely inclined to cut nominal wages because it would hurt the workers morale and eventually their productivity. On the same line, but from a macro perspective, Elsby (2009) provides a partial equilibrium model in which wages cuts decrease productivity of firms. As a result, nominal wages are rigid not only to fall, but also to rise, because any current increase makes more likely future cuts on the same wages. Hall (2005) and Shimer (2005) show instead, that wage rigidities are crucial to capture the business cycle fluctuations in a general equilibrium model featured by labor market with search and matching frictions. ${ }^{5}$ Regarding the second main assumption, that is the process with drift on prices level, it is in line with the experience of the most of the developed countries, at least before the onset of the Great Recession. This assumption allows to replicate the path of price level under a monetary policy of nonzero inflation targeting. Under this policy, the central bank pursues a certain level of inflation, unless unpredictable shocks that potentially move the level from the target. In addition to the literature on trend inflation, that emphasizes on the positive level of inflation in the steady state ${ }^{6}$ this paper is related to the literature that formalizes the long-lasting effects of price inflation on the labor market outcomes. Starting indeed from the seminal contribution by Akerlof et al. (1996), several papers argue on the existence of a long-run Phillips curve. In particular, adding downward nominal wage rigidity in a dynamic stochastic general equilibrium model, Benigno and Ricci (2011), Kim and Ruge-Murcia (2008), Fagan and Messina (2009), Daly and Hobijn (2014) investigate the so-called greasing effects of inflation. ${ }^{7}$ The model economy assumed in

Hyslop (1997), Altonji and Devereux (2000), Lebow et al. (2003), Elsby (2009), Fagan and Messina (2009), Kim and Ruge-Murcia (2009) and Daly et al. (2012). Still using firm-level data, Dickens et al. (2007) make a comparison among different countries. Differently, using industrial-level data Holden and Wulfsberg (2008) and Messina et al. (2010) provide a multi-country analysis of downward nominal wage rigidity.

${ }^{4}$ International evidence based on surveys are for example provided by Holden (2004), Knoppik and Beissinger (2009), Babecky et al. (2010) among others.

${ }^{5}$ Other contributions in search literature with wage rigidities are Christoffel et al. (2009), Gertler and Trigari (2009), Barnichon (2010), Blanchard and Gali (2010), Abbritti and Fahr (2011).

${ }^{6}$ See for instance Ascari (2004), Ascari and Sbordone (2014).

${ }^{7}$ On the same topic, Fahr and Smets (2010) argue on the greasing effects of inflation in a context of monetary union, while Loboguerrero and Panizza (2006) find that the greasing effects are more relevant in those countries, where the labor market is highly regulated. Fehr and Gotte (2005) stress on the role of nominal rigidity for the long-run Phillips curve, restricting the analysis to Switzerland for the 1990s. They show that during the periods featured by low inflation, unemployment rate is higher in those Swiss cantons that are more affected by downward nominal wage rigidity. Lundborg and Sacklén (2006) study the relationship between low-inflation targeting and long-run unemployment, using Swedish data in the model by Akerlof et al. (1996). They find that in an enviroment of low inflation, any increase of inflation target implies a more proportional reduction of long-run unemployment. Kuttner and Robinson (2010) 
this paper allows to derive a closed-form solution for the long-run Phillips curve like Akerlof et al. (1996) and Benigno and Ricci (2011), but differently from these works, it is able to consider separately the contribution of nominal and real forces. The focus on the role of the variability of inflation and productivity on expected unemployment naturally links this paper with the ones that deal with the effects of aggregate volatility on real variables outcomes. In this respect, the literature has discussed the effects of both nominal $^{8}$ and real volatility. ${ }^{9}$ Lastly, this paper is still related to the literature on the effects of productivity level on labor market equilibrium. Like for the inflation, the drift of productivity sustains the growing dynamics of nominal wages. Since higher levels of productivity imply a lower long-run unemployment rate, the spirit of the paper is similar to the literature claiming that technology progress creates new jobs, rather than destroys them. ${ }^{10}$

The rest of the paper proceeds as follows. Section 2 illustrates the theoretical model, which provides a closed-form solution for the long-run Phillips curve. Section 3 discusses the data and the results of panel regressions. Section 4 describes the robustness checks that support the empirical analysis. Specifically, panel regressions are repeated firstly, with alternative measures of inflation and productivity, secondly with different subperiods, and thirdly with the inclusion of interaction terms that capture the role of nominal rigidities. Section 5 concludes.

\section{Theoretical model}

The theoretical framework here used to study the long-run relationship between unemployment and nominal growth is a dynamic stochastic general equilibrium (DSGE) model featured by downward nominal wage rigidity (DNWR). Although in the reality the relations in the labor market are much more complex than the stylized mechanism here proposed, in order to make the implications as clearer as possible, the model assumes the presence of a social norm that prevents at all any kind of wage cuts. Under this norm, nominal wages can only either increase or remain constant at the level of previous period. More precisely, the social norm can be formalized as the following

argue on the flattening of the long-run Phillips curve in Australia at low inflation level.

${ }^{8}$ The role of inflation volatility in explaining real variables dynamics is studied in several papers that compare different monetary policy rules with US data as Clarida et al. (1999), Svensson (1999), Taylor (1999). In cross-countries analysis instead, Fischer (1993), Judson and Orphanides (1999) argue on the negative effects of inflation volatility on real growth.

${ }^{9}$ For instance in different settings, Hairault et al. (2010) and Benigno et al. (2015) emphasize on the positive impact on unemployment of the second moments of respectively, total factor productivity and labor productivity.

${ }^{10}$ Some examples of works that support the positive relationship between productivity and long-run employment are Bruno and Sachs (1985), Phelps (1994), Blanchard et al.(1995), Blanchard and Wolfers (2000), Staiger, Stock, and Watson (2001), Pissarides and Vallanti (2007), Shimer (2010). 
non-negative constraint,

$$
d \ln W_{t} \geqslant 0
$$

Analogous extreme nominal wage downward rigidity is assumed in Benigno and Ricci (2011), ${ }^{1112}$ with which the following theoretical model shares the main setting. However, an important exception for this model is the introduction of two independent processes on prices and productivity growth, that allows to consider separately the dynamics of nominal and real variables of the model. ${ }^{13}$ The (logs of) price $P_{t}$ and labor productivity $A_{t}$ are assumed to follow two distinct geometric Brownian motions,

$$
\begin{aligned}
d \ln P_{t} & =\mu d t+\sigma_{P} d B_{P, t}, \\
d \ln A_{t} & =g d t+\sigma_{A} d B_{A, t}
\end{aligned}
$$

where $\mu$ and $g$ are the drift coefficients of price and productivity processes; $\sigma_{P}$ and $\sigma_{A}$ are the corresponding volatility coefficients; $B_{P, t}$ and $B_{A, t}$ are the Wiener processes, that are assumed uncorrelated among each other, i.e. $E_{t}\left[B_{P, t}, B_{A, t}\right]$, for any $t$.

The rest of the model is very standard. The economy is composed by a continuum of infinitely lived households, which derive utility from consuming goods and disutility from supplying labor. Each household $j$, with $j \in[0,1]$, is heterogenous given that all its members, i.e. the workers, provide to firms a specific kind of job $l_{t}(j)$. Workers from different households compete in a labor market featured by monopolistic competition. Conversely, firms are homogenous and determine the labor demand by choosing both the aggregate level of labor and the optimal allocation between the different types of labor. Since prices adjust instantaneously, representative firm simply chooses the aggregate labor demand by maximizing the following static profit function with respect to the labor $L_{t}$,

$$
P_{t} Y_{t}-W_{t} L_{t}
$$

In profit maximization, the only constraint faced by firms is the production function, $Y_{t}=A_{t} L_{t}^{\alpha}$, which with $\alpha<1$ admits decreasing returns to scale for the labor input. The first order condition of firm problem equates the nominal wage to the value of marginal labor productivity,

$$
W_{t}=\alpha P_{t} A_{t} L_{t}^{\alpha-1}
$$

\footnotetext{
${ }^{11}$ In Benigno, Ricci and Surico (2015) instead, real wages are allowed to decrease, but only up to a negative threshold, below which they cannot however fall.

${ }^{12}$ Converserly, Fagan and Messina (2009) and Daly and Hobijn (2014) model the wages adjustment $\grave{a}$ la Calvo (1983), as it is commonly used for formalizing price rigidities. They assume that only a share of households, and not the whole set of them, is not allowed to freely choose the wage level.

${ }^{13}$ In Benigno and Ricci (2011) three different geometric Brownian motions are respectively imposed to productivity, nominal spending, labor disutility. In Benigno, Ricci and Surico (2015) instead, it is only assumed a geometric Brownian motion on productivity.
} 
The aggregate labor demand $L_{t}$ is determined from the wage schedule (5). In turn, this aggregate labor demand is composed by the individual demands for any kind of labor, through the following CES aggregate,

$$
L_{t} \equiv\left[\int_{0}^{1} l_{t}(j)^{\frac{\theta_{\omega-1}}{\theta_{\omega}}} d i\right]^{\frac{\theta_{\omega}}{\theta_{\omega}-1}},
$$

where $\theta_{\omega}>1$ represents the elasticity of substitution between labor types. In choosing the optimal demand for any kind of labor, representative firm considers the following Dixit-Stiglitz aggregate wage index, which takes as given all individual nominal wages $W_{t}(j)$ chosen by the households,

$$
W_{t} \equiv\left[\int_{0}^{1} W_{t}(j)^{1-\theta_{\omega}} d i\right]^{\frac{1}{1-\theta_{\omega}}} .
$$

The optimal labor allocation for the representative firm gives the following individual demand schedule for labor type $j$,

$$
l_{t}(j)=\left(\frac{W_{t}(j)}{W_{t}}\right)^{-\theta_{\omega}} L_{t} .
$$

Such downward-sloping individual labor demand is considered among the constraints for household $j$, who sets autonomously the wage she gains, as in Erceg et al. (2000). Households $j$ maximizes the present discount value of instantaneous utility flow with respect to both consumption goods $C_{t}^{j}$ and nominal wage $W_{t}(j)$. The objective function can be written as,

$$
E_{t_{0}}\left[\int_{t_{0}}^{\infty} e^{-\rho\left(t-t_{0}\right)}\left(\ln C_{t}^{j}-\frac{l_{t}(j)^{1+\eta}}{1+\eta}\right) d t\right],
$$

where $\rho>0$ is the preference discount rate and $\eta$ is the inverse of the elasticity of labor supply with respect to the nominal wage. Utility maximization is subject to the individual labor demand (7) and to the nominal intertemporal budget constraint,

$$
E_{t_{0}}\left\{\int_{t_{0}}^{\infty} Q_{t} P_{t} C_{t}^{j} d t\right\}=E_{t_{0}}\left\{\int_{t_{0}}^{\infty} Q_{t} W_{t}(j) l_{t}(j) d t\right\},
$$

with $Q_{t}$ as stochastic discount factor in capital markets, where claims to monetary units are traded. The household intertemporal allocative problem is solved by the first order conditions with respect to consumption at time $t$ and $t+1$, which give the following standard Euler equation,

$$
\frac{1}{R_{t}}=e^{-\rho} E_{t}\left[\frac{C_{t}}{C_{t+1}} \frac{P_{t}}{P_{t+1}}\right]
$$


where $R_{t}$ is the gross nominal interest rate. Since it is assumed that capital markets are complete, the consumption level $C_{t}$ is uniform among the households. The first order condition with respect to the nominal wage determines the optimal level $W_{t}^{*}$ as,

$$
W_{t}^{*}=\mu_{\omega} P_{t} C_{t} L_{t}^{\eta}
$$

The optimal nominal wage is equal to the product between the marginal rate of substitution between consumption and leisure, and the mark-up due to worker monopoly power, $\mu_{\omega} \equiv \frac{\theta_{\omega}}{\theta_{\omega}-1}$. The constraint on nominal wages (1) implies that the current level of nominal wage is not necessary equal to the optimal one. Whenever the optimal wage is lower than the wage prevailing in the previous period, i.e. $W_{t}^{*}<W_{t-1}$, the current level of nominal wage remains fixed at the level of previous period, resulting therefore higher than the optimal level for the current period,

$$
W_{t}=W_{t-1}>W_{t}^{*}
$$

Importantly, so far households are assumed to be myopic with respect to the social norm that prevents nominal wage from falling. In others words, it is assumed that households do not consider the non-negative constraint in choosing the optimal wage. Hence the wage schedule for the myopic households is given by the following,

$$
\begin{aligned}
& \text { if } W_{t}^{*} \geqslant W_{t-1} \Longrightarrow W_{t}=\mu_{\omega} P_{t} C_{t} L_{t}^{\eta}=W_{t}^{*}, \\
& \text { if } W_{t}^{*}<W_{t-1} \Longrightarrow W_{t}=W_{t-1}>W_{t}^{*},
\end{aligned}
$$

which states again that the current level of nominal wage equates the current optimal level if and only if the latter is not lower than the wage prevailing in the previous period. The wage schedule would be slightly different, if it is assumed that households are aware of the downward rigidity. As it is shown in Appendix A.1, in this case the wage chosen by the households would be lower than the optimal wage $W_{t}^{*}$. As emphasized indeed by Elsby (2009), the presence of downward rigidities do not only limit the wages in falling, as it is obvious, but also dampen the wages in moving up. When households include the social norm (1) among the constraints they face in choosing the nominal wage, they implicitly take into account that the likelihood of future cuts in wages also depends on their current choices. The higher they fix nominal wages, when they are allowed to do it, the more likely they are stuck at a high wage, when a negative shock occurs. Households choose then a desired wage lower then the optimal one. The inclusion of the non-negative constraint on nominal wages in households problem complicates seriously the derivation of the wage supply schedule, but eventually it does not modify substantially the shape of the long-run Phillips curve, that remains the core result of the theoretical model. For this reason the main text continues to consider the case of myopic households, that is of households that do not take into account the social norm (1) in their maximization problem. The long-run Phillips curve that relates expected unemployment to the moments of price and productivity processes is derived analytically in closed-form in the following section. 


\subsection{Long-run Phillips curve}

As in Gali (2011), unemployment is defined as the difference between the (logs of) notional labor supply and the current labor demand, $u_{t} \equiv \ln \left(L_{t}^{n}\right)-\ln \left(L_{t}^{d}\right)$. The former is the labor supply provided by workers under a perfect competitive labor market with flexible wages. Its value is recovered by equating the real wage to the marginal rate of substitution between consumption and leisure. In log-terms, it is

$$
\ln W_{t}-\ln P_{t}=\ln C_{t}+\eta \ln \left(L_{t}^{n}\right) .
$$

Since all goods produced by the firms are consumed, it is possible to combine the goods market clearing condition, the labor demand determined by (5) and the notional labor supply determined by (13) in order to rewrite the unemployment rate as,

$$
u_{t}=\chi\left(\ln W_{t}-\ln P_{t}-\ln A_{t}-\bar{\alpha} \ln \alpha\right)
$$

where $\chi$ and $\bar{\alpha}$ are defined as $\chi \equiv \frac{1+\eta}{\eta(1-\alpha)}$ and $\bar{\alpha} \equiv \frac{\alpha+\eta}{1+\eta}$. Conveniently, the (log of) notional supply $L_{t}^{n}$ can be rewritten as the sum of the (log of) labor supply $L_{t}^{*}$, provided by workers under a monopolistic competitive labor market with flexible wages, and the constant term $\frac{1}{\eta} \ln \mu_{\omega}$, which defines the natural unemployment as in Gali (2011),

$$
\ln \left(L_{t}^{n}\right)=\ln \left(L_{t}^{*}\right)+\frac{1}{\eta} \ln \mu_{\omega}
$$

Plugging (14) into (15) gives the gap between supply and demand in a labor market featured by monopolistic competition,

$$
\ln \left(L_{t}^{*}\right)-\ln \left(L_{t}^{d}\right)=\chi\left(\ln W_{t}-\ln P_{t}-\ln A_{t}-\bar{\alpha} \ln \alpha\right)-\frac{1}{\eta} \ln \mu_{\omega},
$$

The wage norm assumed in the model ensures that, whenever nominal wage is equal to its optimal level, i.e. $W_{t}=W_{t}^{*}$, the economy behaves like with flexible wages, thereby labor market clears, i.e. $\ln \left(L_{t}^{*}\right)=\ln \left(L_{t}^{d}\right)$. Considering (16) and (14), this means that in that case unemployment is constant and equal to its natural level. Whenever instead, the current nominal wage is higher than its optimal level, unemployment is no more constant, but rises above its natural level. In this case, the labor gap is positive and unemployment follows a dynamics led by the underlying processes of prices and productivity. Taking the unemployment equation (14) in differential terms, it is straightforward to note that whenever lower constraint binds, i.e. $d W_{t}=0$, unemployment variations are proportional to $d \ln P_{t}$ and $d \ln A_{t}$. Specifically, above the lower barrier $\frac{1}{\eta} \ln \mu_{\omega}$, unemployment moves like a geometric Brownian motion with a drift $-\chi(\mu+g)$ and volatility coefficient $-\chi\left(\sigma_{P}+\sigma_{A}\right)$. Unemployment follows thus a regulated Brownian 
motion with a negative drift, given that $\chi>0$. Standard results guarantee that unemployment has a stationary distribution depending on trend and volatility coefficients of price and productivity processes, ${ }^{14}$

$$
f(x)=\frac{2 \vartheta}{\chi \tilde{\sigma}^{2}} e^{\frac{2 \vartheta}{\chi^{2}}(x-\bar{u})}
$$

where $\bar{u}, \vartheta$ and $\tilde{\sigma}^{2}$ are respectively defined as $\bar{u} \equiv \frac{1}{\eta} \ln \mu_{\omega}, \vartheta \equiv \mu+g$ and $\tilde{\sigma}^{2} \equiv \sigma_{P}^{2}+\sigma_{A}^{2}$. From the stationary distribution (17), it is possible to determine the long-run expected value for unemployment,

$$
E\left[u_{\infty}\right]=\bar{u}+\frac{\chi \tilde{\sigma}^{2}}{2 \vartheta}
$$

Equation (18) is the key equation of the model. It shows that, apart from the natural level of unemployment $\bar{u}$, the long-run expected value of unemployment depends positively on the quantity $\tilde{\sigma}^{2}$, that represents the sum of the variability coefficients of price and productivity processes, and negatively on the quantity $\vartheta$, that represents the sum of the trend coefficients. The assumption of two separated processes on price and productivity allows to disentangle the contributions of nominal and real dynamics on expected unemployment. However, since the moments of inflation and productivity growth enters into equation (18) symmetrically, their contributions are equal from a qualitatively point of view. Equation (18) has the implication that the expected variation in unemployment is null. Taking then i) the long-run differentials and ii) the expected values of the both sides of equation (14), it derives the following,

$$
E\left[d \ln W_{\infty}\right]=\mu+g
$$

The expected long-run dynamics of nominal wages, that is the expected long-run nominal wage inflation, is given by the sum of the trends of price inflation and the trend of productivity. Combining equations (19) and (18) yields that the expected long-run unemployment depends directly on the expected long-run nominal wage inflation,

$$
E\left[u_{\infty}\right]=\bar{u}+\frac{\chi \tilde{\sigma}^{2}}{2 E\left[d \ln W_{\infty}\right]} .
$$

Equation (20) relates the unemployment rate with the nominal wage inflation, as originally stated by Phillips (1958). This long-run version of Phillips curve (LRPC) shows that, in an environment featured by downward nominal wage rigidity, the expected unemployment at low frequencies depends on how much nominal wages grow on average. The higher is the trend in nominal wage inflation, the lower is the expected value of unemployment. Taking for instance, a given interval of time, the higher is the level of

\footnotetext{
${ }^{14}$ For more details see Harrison (1985).
} 
wage inflation, the fewer are the episodes on average, during which negative realizations of normally distributed shocks require a fall in the optimal nominal wage. Not only, whenever optimal nominal wage effectively needs to fall, it decreases less on average, because the wage inflation alleviates the impact of any shock. As a consequence on labor margin dynamics, the short-run unemployment increases above its natural level at a lower frequency and for a lower amount than it would do with lower levels of wage inflation. Straightforwardly, the decrease of the frequency and of the size of short-run unemployment reduces in turn, the expected unemployment in the long-run.

\section{International evidence}

This section tests on a cross-country basis, the main conclusions of the theoretical model. The empirical analysis aims to study the relationship between long-run unemployment and the moments of both inflation and productivity growth processes. The associations this analysis wishes to investigate, are provided by equation (18), that makes the expected long-run unemployment depending on the normalized variances of price inflation and productivity growth, with normalization rate given by the sum of the nominal and real trends. To test if the theoretical prescriptions are confirmed in the data even with a simple empirical strategy, the panel regression model considered is linear and static. Equation (18) is approximated by a specification that makes long-run unemployment depending linearly on the moments of both inflation and productivity dynamics. The individual contributions of trends and volatilities are studied using an international dataset, that presents two important features. The first one is that, along with the variability of cross-sectional dimension, the dataset considers the variability of times-series dimension, since it collects observations for each country on annually basis from 1961 to 2011. Although the analysis is focused on the long-run, taking just the simple averages of the variables for the full sample interval, do not allow to keep track of the structural changes, that have affected the variables dynamics during the Great Moderation and the Great Recession. To take into account the variability at low frequencies of the data, instead of using the row times series collected, panel regressions use the means and the standard deviations of different variables, calculated on 10-year rolling windows basis. The second feature of the dataset concerns the sample of countries analyzed. The international comparison is limited to advanced countries. ${ }^{15}$ This choice is motivated by the necessity of collecting sufficiently long series for all variables. Summing up, for each country are calculated yearly series i) for the levels of unemployment rate, inflation rate and productivity growth rate and ii) for the standard deviations of inflation and

\footnotetext{
${ }^{15}$ The countries considered in the sample are Australia, Austria, Belgium, Canada, Chile, Czech Republic, Denmark, Estonia, Finland, France, Germany, Greece, Hungary, Ireland, Israel, Italy, Japan, South Korea, Luxembourg, Mexico, Netherlands, New Zealand, Norway, Poland, Portugal, Russian Federation, Slovenia, Spain, Sweden, Switzerland, Turkey, United Kingdom, United States.
} 
productivity rate. For both i) and ii), any value of the series corresponds respectively, to the average and to the standard deviation of the variable levels observed in the previous 10 years. The unbalanced dataset so compiled, is used in panel regressions with fixed effect and time dummies. The next Section 3.1 describes in details the data used, while the following Section 3.2 discusses the results of panel regressions.

\subsection{Data}

The unemployment rate is the endogenous variable for all specifications considered below. The unemployment rate series is recovered by OECD Annual Labor Force Statistics, as the yearly percentage of unemployed workers on civilian labour force (YGTT06PC_ST).

To measure the mean and the volatility of inflation at low frequencies, two alternative variables are compared in the baseline specification. The first one is the growth rate of CPI index for all items, which is the variable that probably best fits the growing process for prices assumed in the theory. As argued above, under an exogenous process with drift, the price level has a pattern similar to the one that it would follow if the monetary authority pursued a policy of strict inflation targeting. Since the most of the central banks, which have adopted an inflation targeting as monetary policy strategy, have taken the growth rate of consumer prices as the benchmark on which decided the target, the choice of CPI increments to measure level and volatility of price inflation is very reasonable. Such measure of price inflation is also used in other empirical contributions, that for instance discuss the real effects of inflation, as Fischer (1993) and Judson and Orphanides (1996). Albeit the analysis of these contributions focus on the short-run effects of inflation on growth, they shares with this paper the emphasis on the relation between real variables and inflation volatility. ${ }^{16}$ The series for consumer inflation are recovered by the OECD Consumer price indices dataset, as the percentage changes on the previous year of CPI index for all items (CPALTT). The alternative variable used to measure long-run inflation moments is the GDP deflator, whose availability of data is sufficiently long to make feasible the comparison with the CPI index for all goods. Such comparison is useful because, although CPI index and GDP deflator are both commonly used in literature to measure the price inflation, they differ significantly with respect to the variability of the series. Increments of GDP deflator, which are provided by the OECD Annual National Accounts as the percentage changes on the previous year, result much less volatile than the increments of CPI index. ${ }^{17}$

\footnotetext{
${ }^{16}$ Differently from Judson and Orphanides (1996), in this paper the inflation volatility is not computed using quarterly observations, because annually data appears more informative for an analysis at low frequencies.

${ }^{17}$ Considering for instance the full database, the standard deviation for the CPI inflation series is 0,54 versus 0,20 for GDP deflator variations.
} 
Since the theoretical model presented above, considers the labor input as the single factor used in the production process, the mean and the volatility of productivity growth are measured through the variations of the marginal contribution of labor. Given that observations on total hours are very short for several countries in the sample, the marginal contribution of labor is measured in terms of output per employed workers. The labor productivity growth is obtained by the yearly increments of the ratio between the real gross value added at basic prices and the total employment. For the former, data are provided by OECD Annual National Accounts, through the series of gross domestic product calculated according to output approach at constant prices and constant PPPs. For the employment, data are given by Annual Labor Force Statistics, through the series of total employment (YGTT04L1_ST) and of civilian employment (YGTT08L1_ST). When data available are sufficiently long, the series on total employment are preferred. ${ }^{18}$ Since for the most of the countries, the total employment series start in the Seventies, ${ }^{19}$ the interval of time actually analyzed in the panel regressions for those countries, is restricted by about ten years.

\subsection{Panel regressions}

In the baseline specification, unemployment rate $u_{i, t}$ for country $i$ at time $t$, is regressed over level and volatility terms of inflation and labor productivity growth, as the following equation shows,

$$
u_{i, t}=\beta_{1} \mu_{i, t}+\beta_{2} g_{i, t}+\beta_{3}\left(\sigma_{P}\right)_{i, t}+\beta_{4}\left(\sigma_{A}\right)_{i, t}+\alpha_{i}+\lambda_{t}+\varepsilon_{i, t}
$$

where $\mu_{i, t}$ and $\left(\sigma_{P}\right)_{i, t}$ indicate respectively, the mean and the standard deviation of inflation. Analogously, $g_{i, t}$ and $\left(\sigma_{A}\right)_{i, t}$ indicate the mean and standard deviation of labor productivity growth. The further regressors $\alpha_{i}$ and $\lambda_{t}$ indicate the country and time fixed effects. These dummy variables capture the effects on unemployment due to factors related to the structural characteristics of any country and to the specific events happened during the years analyzed.

The estimation results are shown in Table 1. In specifications 1 and 2, unemployment at low frequencies is regressed only over inflation terms. With either CPI inflation or GDP deflator increments, unemployment results to depend negatively on inflation mean and positively on inflation volatility. Similarly, in specification 4 unemployment is regressed only on labor productivity terms. Still the signs of the estimated coefficients for productivity are in line with the theory, that is negative for the mean and positive for the volatility, but they are not statistically significant. When in specifications 5-6,

\footnotetext{
${ }^{18}$ Civilian employment is taken as the measure of labor input for Austria, Chile, Greece, Israel, Japan, South Korea, Mexico, Poland, Slovenia, Sweden, Switzerland.

${ }^{19}$ The only countries in the sample with total employment series starting before than 1970 are Denmark, France, South Korea, Netherlands, United Kingdom.
} 
both real and nominal moments are included into regressions, all the four coefficients are statistically significant and with the signs predicted by the theory. Independently from how inflation is measured, in specifications 5 and 6 unemployment is affected negatively by the levels and positively by the volatilities of both price and productivity growth.

Importantly, all specifications that include mean and standard deviation of inflation present an appropriated $R^{2}$ for fixed effect models, i.e. the LSDV- $R^{2}$-where LSDV indicates the regression method of Least Squares Dummy Variables- higher than 0,75. The fitness of the estimates confirm that, albeit the specifications used in panel regressions are only linear approximations of the non-linear long-run Phillips curve (18), the data well support the opposite effects of drifts and volatilities on long-run unemployment. These effects are especially remarkable for the inflation terms, because even at low frequencies, the level and the volatility of price growth are highly positively correlated. ${ }^{20}$ This positive correlation does not however prevent the level and the variability of inflation from having an opposite impact on the long-run unemployment mean. ${ }^{21}$

\section{Robustness}

In the following paragraphs the panel regressions are repeated in order to check the robustness of the estimation results under different conditions. The relation between unemployment and the moments of price and productivity growth is tested firstly, considering alternative measures of inflation and productivity, secondly, dividing the full sample interval into two sub-periods, and thirdly, taking into account the different degree of nominal rigidity between the countries.

\subsection{Alternative measures of inflation and productivity}

As discussed in Section 2.1, the unemployment equation (18) can be conveniently rewritten as equation (20) that makes the expected long-run unemployment depending directly on the expected long-run nominal wage inflation. To test this alternative equation, estimations are repeated using mean and standard deviation of nominal wage inflation instead of price inflation. The dynamics of nominal wage is calculated by collecting data on labor compensation. The series considered is provided by the OECD Annual

\footnotetext{
${ }^{20}$ Considering the full dataset, the correlation among mean and standard deviation computed over 10-year rolling windows is 0,95 and 0,88 respectively, for the increments of CPI index and of deflator index.

${ }^{21}$ To mitigate the positive correlation among level and volatility of price growth in the short-run, Judson and Orphanides (1996) consider an intra-year measure of inflation volatility that uses quarterly data. So to check the robustness of the above results with quarterly data, panel regressions described in Section 3.2 have been repeated with the same intra-year measure of inflation volatility used by Judson and Orphanides (1996). Estimation results are analogous to the ones obtained with annually data and are available upon request.
} 
National Accounts, as the compensation of labor at current prices and current PPPs. Specification 3 in Table 1 shows the results obtained by regressing unemployment mean over average and standard deviation of wage inflation, whereas specification 7 shows the results obtained by regressing unemployment mean over averages and standard deviations of both wage inflation and labor productivity growth. In both specifications the estimated coefficient related to the level of wage inflation is negative as the theory suggests. Still the estimated coefficient of the wage inflation variability is negative, but it is not statistically significant when labor productivity terms are included. ${ }^{22}$

To check also the robustness of the baseline estimations with an alternative measure of productivity, the panel regressions are run using the total factor productivity (TFP) instead of the marginal contribution of labor. The TFP is a more general measure of productivity and thus, might be more easily interpreted as the last force that leads the real growth. Using the empirical model (21), the estimation exercise is repeated with the series of mean and standard deviation of TFP growth, calculated as in Pissarides and Vallanti (2007) as follows,

$$
d \ln A_{t}=\frac{1}{\alpha}\left[d \ln Y_{t}-(1-\alpha) d \ln K_{t}-\alpha d \ln L_{t}\right],
$$

where $A_{t}$ is the level of TFP, $Y_{t}$ is the GDP at constant price and national currencies, $K_{t}$ is the capital stock, $L_{t}$ is the total employment. ${ }^{23}$ As shown in Table 2, independently from how it is measured the price inflation, when nominal and real moments are considered contemporaneously, as in specifications 9 and 10, all estimated coefficients are in line with the theory. Furthermore they are all statistically significant, except for the TFP growth mean when inflation is measured with GDP deflator. Above results with labor productivity are also confirmed in specification 11, where the regressors are means and standard deviations of TFP and nominal wage inflation. Unemployment is indeed related negatively to the wage inflation mean and positively to the real volatility. Finally, although the substitution of labor productivity with TFP reduces significantly the number of observations used in the regressions, the appropriate $R^{2}$ remains high, above than 0,8 for all specifications.

\footnotetext{
${ }^{22}$ The fact that both level and variability of nominal wage inflation affect negatively long-run unemployment is quite intriguing to the extent that, differently from price inflation, the correlation between mean and standard deviation of nominal wage inflation is lower and equals to 0,31 .

${ }^{23}$ In details, for the real output $Y$ and the capital stock $K$ are used the gross domestic product (expenditure approach) and the gross capital formation. Both are taken at constant prices and constant PPPs. For the labor input $L$ is used the series of the total employment (YGTT04L1_ST) when available, otherwise the series of civilian employment (YGTT08L1_ST). The labor share $\alpha$ is simply defined as the ratio between aggregate labor compensation and GDP. The ratio is recovered as in Pissarides and Vallanti (2007), who use the following variables: the labor cost -measured as the compensation of employees at current prices and current PPPs-; the gdp deflator; the labor input; the total number of self-employed -which are given by Annual Labor Force Statistics (YGTT22L1_ST)- and the real output.
} 


\subsection{Controlling for sub-periods}

To assess how the empirical evidence evolves during the time interval analyzed, panel regressions are run for sub-periods of the full interval considered in previous sections. The full sample interval spans indeed a long period that also includes the Great Moderation. To control for the structural break of the onset of the Great Moderation, after which the volatility of many aggregate variables drastically reduced, the full interval is divided into two sub-periods. More precisely, following Kim and Nelson (1999) and Stock and Watson (2002), the cut-off that separates the two sub-periods is fixed at the end of 1983. Panel regressions are repeated for the two sub-periods, using as data only price inflation and labor productivity for comparability with the benchmark estimations in Section 3.2. In Table 3, unemployment is regressed over mean and standard deviation of CPI inflation and labor productivity growth. In specification 12 data goes up to 1983 , while in specification 13 data goes from 1984 on. Specifications 14 and 15 are considered the same sub-periods of 12 and 13, but price inflation is measured by the GDP deflator and not by the CPI index. Estimated coefficients for specifications using data for the sub-period preceding the Great Moderation are never significant. Conversely, the coefficients for specifications using data for the following sub-period are significant and in line with the theory, at least for mean and volatility of price inflation and for volatility of labor productivity. These results indicate that, restricting the analysis to a period in which many countries experienced not only a strong reduction in the variability of price inflation, but also in the level of it, the long-run real effects of pure nominal dynamics are enhanced. The evidence of a solid relation between unemployment and nominal dynamics during the last decades supports the general validity of the theoretical model. According to it, the long-run relation linking nominal and real sides of the economy should be dampened, when the level and the variability of inflation are high and the downward rigidities on nominal wages are less likely to bind. This is exactly what occurred during the sample period before the Great Moderation, for which the data does not support the conclusions of the model. To investigate more on the relevance of downward nominal wage rigidity in ensuring a non-vertical long-run Phillips curve, the following section studies how this relation is influenced by the different rate of inflation between the countries.

\subsection{Nominal rigidity interactions}

Along with the growing processes that lead real and nominal sides of the economy, the existence of long-run Phillips curve detected in Section 2.1 is guaranteed by the presence of downward nominal wage rigidity. Without a constraint on nominal wages variations, wages would be free to fluctuate and unemployment would remain fixed at its natural level. Hence, price and productivity dynamics should play a predictable role for long-run unemployment only for those economies really affected by downward 
rigidities on nominal wages. Unfortunately, the degree of wage rigidity across different countries is not easily measurable through a single variable. However, it is equally possible to discriminate the countries with respect to the rigidities in the labor market, by considering some proxies that help to understand the relevance of the frictions that prevent wages from fluctuating freely. One of these proxies is the average value of inflation rate. It is clear indeed, that the level of inflation pushes upward the nominal wages, making less relevant, ceteris paribus, the presence of downward rigidities. Card and Hyslop (1997) provide empirical evidence of this fact, showing empirically that the share of wages subject to rigidities is higher when wage inflation is low. As an immediate consequence for the cross-country analysis, economies that historically register high levels of inflation, should be the ones in which nominal wage dynamics is less constrained, and in turn, the relations described by long-run Phillips curve (18) should be weaker. In order to assess if the long-run relation between unemployment and the moments of price and productivity growth, changes effectively according to how heavy are the nominal rigidities, the country sample is divided into two categories, that include respectively, countries featured by high and low mean inflation. Table 5 illustrates for each country, the mean of inflation over the full sample period. Inflation is calculated using three different measures: the CPI index, the GDP deflator and the nominal compensation for employees. A dummy variable $\delta_{\pi, i}$ assigns 1 to those countries with the inflation mean above the median of the sample, and 0 to those with the inflation mean below the median. This dummy enters into the empirical model through the interaction terms with the regressors of the baseline specification discussed above. The linear regression model used for estimations becomes the following,

$$
\begin{aligned}
u_{i, t}= & \beta_{1} \mu_{i, t}\left(1+\beta_{5} \delta_{\pi, i}\right)+\beta_{2} g_{i, t}\left(1+\beta_{6} \delta_{\pi, i}\right)+ \\
& +\beta_{3}\left(\sigma_{P}\right)_{i, t}\left(1+\beta_{7} \delta_{\pi, i}\right)+\beta_{4}\left(\sigma_{A}\right)_{i, t}\left(1+\beta_{8} \delta_{\pi, i}\right)+\alpha_{i}+\lambda_{t}+\varepsilon_{i, t},
\end{aligned}
$$

Table 6 shows the estimates obtained from three specifications that have in common the regression equation (22), but measure differently the inflation. The results are very easy to interpret for specifications 16 and 17, that use series of price inflation. Similarly to what shown by specification 5 and 6 , for the mean and the standard deviation of the price growth and for the mean of the labor productivity growth, the estimated impacts on long-run unemployment are statistically significant and with the signs coherent with the theory. Still for the interactions of mean and standard deviation of the price inflation with the inflation dummy, the estimated coefficients are statistically significant, but the signs are opposite with respect to the theory. For countries with high inflation mean, which eventually are the only ones with a regression equation containing the interaction terms, because $\delta_{\pi, i}=1$, the additional contribution of inflation and productivity mean is positive, whereas the additional contribution of inflation volatility in negative. It follows that for countries with high inflation, the overall impact of price inflation and productivity growth on long-term unemployment is substantially dampened with 
respect to the impact for countries with low inflation, whose additional contributions of interaction terms are null, given that $\delta_{\pi, i}=0$. Therefore, the estimations suggest again that the explicative role of price and productivity growth for long-run unemployment is weaker for those countries in which prices pressure is heavier. This result is in common with Akerlof et al. (1996), Benigno and Ricci (2011), Daly and Hobijn (2014), who all show that the long-run Phillips curve is bent such that the trade-off between inflation and unemployment is higher for low inflation level, whereas disappears as long as it increases. Similar conclusions are obtained when inflation is measured by the nominal wage growth, as in specification 18. Focusing on the direct effect of wage inflation level on unemployment at low frequencies, the estimated correlation is statistically significant and negative like in specification 7 . But the correlation changes the sign, becoming positive, when one looks to the effect of interaction term for wage inflation level. Like in the case of price growth, it derives that the overall effect of wage inflation level on long-run unemployment is mitigated for those countries, where wages increase more on average and the downward rigidities are less severe.

\section{Conclusions}

This paper studies the long-run relation between unemployment and the leading forces that drive the nominal growth, that is productivity and inflation. This paper emphasizes that drifts and volatilities of productivity and inflation have opposite effects on expected unemployment in the long-run, especially in those economies more affected by downward nominal wage rigidities. Intuitively, the drifts are negative related to expected unemployment, because they sustain the nominal growth, reducing in turn the probability that, for a given negative shock, i) nominal wages hit the lower bound, ii) the labor margin compensates, and iii) the expected long-run unemployment lies above the natural level. On the other side, the volatilities of productivity and inflation are positively related to the expected unemployment, because for any given trend in nominal growth, they amplify the fluctuations of variables making less likely the free adjustment of the wages and, in a longer perspective, more likely an unemployment rate above than the natural level. These associations are firstly derived in the theory through a dynamic stochastic general equilibrium model featured by i) Brownian motions with drift for productivity and price growth and ii) downward rigidity for nominal wages. The theoretical model allows to obtain a long-run Phillips curve in closed form, which relates the long-run expected unemployment with the dynamics of productivity and prices. Secondly, the associations are tested in the data through panel estimations with fixed effects, which consider a linear approximation of the Phillips curve derived in the theory. Long-run mean of unemployment is regressed on averages and standard deviations at low frequencies of productivity and price growth. Regressions are run using a dataset that includes annual observations for the most of OECD members from 1961 
to 2011. Panel estimations suggest that, especially when the presence of nominal wage rigidities is heavy because the inflation pressure is sluggish, the relationship between unemployment and the dynamics of productivity and prices is well established in the data.

Despite it is not explicitly studied in the paper, the policy implication deriving from these findings is that monetary policy might be effective in the long-run. Focusing on the nominal dynamics of the economy, the analysis here developed suggests that, whenever wages are regularly sticky to adjust downwardly, any measure aimed to foster the nominal growth contributes to achieve the full employment equilibrium. Meanwhile, any measure aimed to stabilize the fluctuations of nominal growth alleviates the harmful effects of macroeconomic volatility on labor market. Eventually, policymakers should not be particularly adverse to measures that guarantee not only that prices effectively grow at a positive rate in the long-run, but also that this growth remains firmly anchored to the target. The effectiveness of the monetary policy in the long-run needs however to be further investigated. More specifically, the long-run effects of keeping the inflation stable around the target do not seem to be sufficiently explored in the literature. To shed the light on this point, two strategies are in order in my future research. The first one aims to study the effects of macroeconomic volatility with a different theoretical model, which admits really a positive unemployment rate in the steady state, and not simply a positive rate of not-employment as in this paper. This kind of model should be featured by search and matching frictions in the labor market. In this framework, the effects of the volatility on the matching between vacancies and job seekers are crucial, because at the end, determine the level of unemployment in the steady state. The second strategy aims instead, to evaluate empirically the comovement between unemployment and macroeconomic volatility at low frequencies. A time-varying parameters VAR with heteroskedastic innovations might be a feasible instrument to detect how the unconditional means of unemployment and volatility have evolved in the last decades. Through the spectral analysis, it is moreover possible to provide some insights on the variability of inflation in the long-run, since it allows to isolate the contribution of low frequency components to inflation variance from the contribution of high frequency components. 


\section{References}

Abbritti, Mirko \& Stephan Fahr, (2011). "Macroeconomic implications of downward wage rigidities," Working Paper Series 1321, European Central Bank.

Akerlof, George A. \& William R. Dickens \& George L. Perry, (1996). "The Macroeconomics of Low Inflation," Brookings Papers on Economic Activity, Economic Studies Program, The Brookings Institution, vol. 27(1), pages 1-76.

Akerlof, George A. \& William R. Dickens \& George L. Perry, (2000). Near-Rational Wage and Price Setting and the Long-Run Phillips Curve. Brookings Papers on Economic Activity 1:1-60.

Altonji, Joseph G., \& Paul J. Devereux (2000), "The extent and consequences of downward nominal wage rigidity," in (ed.) 19 (Research in Labor Economics, Volume 19), Emerald Group Publishing Limited, 383-431.

Ascari, Guido, (2004). "Staggered Prices and Trend Inflation: Some Nuisances," Review of Economic Dynamics, Elsevier for the Society for Economic Dynamics, vol. $7(3)$, pages 642-667, July.

Ascari, Guido \& Argia M. Sbordone, (2014). "The Macroeconomics of Trend Inflation," Journal of Economic Literature, American Economic Association, vol. 52(3), pages 679-739, September.

Babecky, Jan \& Philip Du Caju \& Theodora Kosma \& Martina Lawless \& Julián Messina \& Tairi Room, (2010). "Downward Nominal and Real Wage Rigidity: Survey Evidence from European Firms," Scandinavian Journal of Economics, Wiley Blackwell, vol. 112(4), pages 884-910, December.

Baker, Scott R. \& Nicholas Bloom \& Steven J. Davis, (2015). "Measuring Economic Policy Uncertainty," NBER Working Papers 21633, National Bureau of Economic Research, Inc.

Ball, Laurence. (1997). Disinflation and the NAIRU. In C.D. Romer and D.H. Romer (eds.) Reducing Inflation: Motivation and Strategy (pp. 167-194). Chicago: University of Chicago Press.

Ball, Laurence. (1999). Aggregate demand and long-run unemployment. Brooking Papers on Economic Activity 2: 189-251.

Ball, Laurence \& Gregory Mankiw \& David Romer, (1988). The New Keynesian Economics and the Output-Inflation Trade-off, Brookings Papers on Economic Activity, pp. 1-82.

Ball, Laurence \& Robert Moffitt, (2002). Productivity Growth and the Phillips Curve. In The Roaring Nineties: Can Full Employment be Sustained?, edited by A. B. Krueger and R. Solow. New York: Russell Sage Foundation.

Barnichon, Regis (2010). "Productivity and Unemployment over the Business Cycle," Journal of Monetary Economics 57 (2010), 1013-1015.

Benigno, Pierpaolo \& Luca Antonio Ricci, (2011). "The Inflation-Output Trade- 
Off with Downward Wage Rigidities," American Economic Review, American Economic Association, vol. 101(4), pages 1436-66, June.

Benigno Pierpaolo \& Luca Antonio Ricci \& Paolo Surico, (2015). "Unemployment and Productivity in the Long Run: The Role of Macroeconomic Volatility," The Review of Economics and Statistics, MIT Press, vol. 97(3), pages 698-709, July.

Bewley, Truman F. (1995) "A Depressed Labor Market as Explained by Participants," American Economic Review, 85, 250-254.

Bewley, Truman F. (1999). Why Wages Don’t Fall During a Recession, Cambridge, MA: Harvard University Press.

Blanchard, Olivier \& Jordi Galí, (2010). "Labor Markets and Monetary Policy: A New Keynesian Model with Unemployment," American Economic Journal: Macroeconomics, American Economic Association, vol. 2(2), pages 1-30, April.

Blanchard, Olivier \& Robert Solow \& Beth Anne Wilson, (1995). "Productivity and Unemployment," mimeo Massachusetts Institute of Technology.

Blanchard, Olivier \& Justin Wolfers, (2010). "The Role of Shocks and Institutions in the Rise of European Unemployment: The Aggregate Evidence," Economic Journal 110, 1-33.

Bruno, Michael \& Jeffrey. D. Sachs, (1985). "Economics of Worldwide Stagflation,".Cambridge, Massachusetts, Harvard University Press.

Calvo, Guillermo A., (1983) "Staggered Prices in a Utility-Maximizing Framework." Journal of Monetary Economics, 12, 383-98.

Christoffel, Kai \& Keith Kuester \& Tobias Linzert, 2009). The role of labor markets for euro are a monetary policy, European Economic Review, 53(8), 908 - 936

Daly, Mary C.\& Bart Hobijn, (2014), "Downward Nominal Wage Rigidities Bend the Phillips Curve". Journal of Money, Credit and Banking, 46: 51-93.

Daly, Mary C.\& Bart Hobijn \& Brian T. Lucking (2012) "Why Has Wage Growth Stayed Strong?", FRB SF Economic Letter 2012-10, April 2, 2012.

Dickens, William T. \& Lorenz F. Goette \& Erica L. Groshen \& Steinar Holden \& Julian Messina \& Mark E. Schweitzer \& Jarkko Turunen \& Melanie E. Ward-Warmedinger, (2007) "How Wages Change: Micro Evidence from the International Wage Flexibility Project," Journal of Economic Perspectives, 21, 195-214.

Dixit, Avinash (1991), "A Simplified Treatment of the Theory of Optimal Regulation of Brownian Motion," Journal of Economic Dynamics and Control 15, 657-673.

Dumas, Bernard (1991), "Super Contact and Related Optimality Conditions: A Supplement to Avinash Dixit's: A simplified Exposition of Some Results Concerning Regulated Brownian Motion," Journal of Economic Dynamics and Control, vol. 15(4), pp. 675-685.

Erceg, Christopher J.\& Dale W. Henderson \& Andrew T. Levin (2000), "Optimal Monetary Policy with Staggered Wage and Price Contracts," Journal of Monetary Economics, 46 (2), pp. 281-313. 
Elsby, Michael W.L. (2009) "Evaluating the Economic Significance of Downward Nominal Wage Rigidity," Journal of Monetary Economics, 56, 154-169.

Fagan, Gabriel \& Julian Messina, (2009). "Downward wage rigidity and optimal steady-state inflation," Working Paper Series 1048, European Central Bank.

Fahr, Stephan \& Frank Smets, (2010). "Downward Wage Rigidities and Optimal Monetary Policy in a Monetary Union," Scandinavian Journal of Economics, Wiley Blackwell, vol. 112(4), pages 812-840, December.

Fair, R.C. (2000). Testing the NAIRU model for the United States. The Review of Economics and Statistics 82 (1): 64-71.

Fehr, Ernst, \& Lorenz Goette, (2005). Robustness and Real Concequences of Nominal Wage Rigidity. Journal of Monetary Economics, 52(4), 779-804.

Fischer, Stanley (1993), The Role of Macroeconomic Factors in Growth, Journal of Monetary Economics, December , 485-512.

Fisher, Mark E. \& Seater, John.J. (1993). Long-run neutrality and supeneutrality in an ARIMA framework. The American Economic Review, 83: 402-415.

Gertler, Mark \& Antonella Trigari, (2009). "Unemployment Fluctuations with Staggered Nash Wage Bargaining," Journal of Political Economy, University of Chicago Press, vol. 117(1), pages 38-86, 02.

Hairault, Jean-Olivier \& Francois Langot \& Sophie Osotimehin, (2010). "Matching frictions, unemployment dynamics and the cost of business cycles," Review of Economic Dynamics, Elsevier for the Society for Economic Dynamics, vol. 13(4), pages 759-779, October.

Hall, Robert. E. (2005). "Employment Fluctuations with Equilibrium Wage Stickiness," American Economic Review 95 (2005), 50-65.

Harrison, Michael J., (1985). Brownian Motion and Stochastic Flow Systems, John Wiley and Sons, New York.

Holden, Steinar (2004). The Costs of Price Stability-Downward Nominal Wage Rigidity in Europe. Economica, 71, 183-208.

Holden, Steinar \& Wulfsberg Fredrik, (2008). "Downward Nominal Wage Rigidity in the OECD," The B.E. Journal of Macroeconomics, De Gruyter, vol. 8(1), pages 1-50, April.

Judson, Ruth \& Athanasios Orphanides, (1999). "Inflation, Volatility and Growth," International Finance, Wiley Blackwell, vol. 2(1), pages 117-38, April.

Kahn, Shulamit, (1997). "Evidence of Nominal Wage Stickiness from Microdata," American Economic Review, American Economic Association, vol. 87(5), pages 9931008, December.

Kim, Chang-Jin \& Charles R. Nelson, (1999). "Has The U.S. Economy Become More Stable? A Bayesian Approach Based On A Markov-Switching Model Of The Business Cycle," The Review of Economics and Statistics, MIT Press, vol. 81(4), pages 608-616, November. 
Kim, Jinill \& Ruge-Murcia, Francisco J., (2009). "How much inflation is necessary to grease the wheels?," Journal of Monetary Economics, Elsevier, vol. 56(3), pages 365-377, April.

King, R.G. \& Watson, M.W. (1994) The post-war U.S. Phillips curve: a revisionist econometric history. Carnegie-Rochester Conference Series on Public Policy 41: 157219.

Knoppik, Christoph \& Thomas Beissinger, (2009). "Downward nominal wage rigidity in Europe: an analysis of European micro data from the ECHP 1994-2001," Empirical Economics, Springer, vol. 36(2), pages 321-338, May.

Kuttner, Ken \& Robinson, Tim, (2010). "Understanding the flattening Phillips curve," The North American Journal of Economics and Finance, Elsevier, vol. 21(2), pages 110-125, August

Lebow, David A \& Raven E. Saks \& Beth Anne Wilson (2003), "Downward Nominal Wage Rigidity: Evidence from the Employment Cost Index," B.E. Journal of Macroeconomics: Advances, 3, issue 1.

Loboguerrero, Ana Maria \& Ugo Panizza (2006). "Does Inflation Grease the Wheels of the Labor Market?," Contributions to Macroeconomics, Berkeley Electronic Press, vol. 6(1), pages 1450-1450.

Lundborg, Per \& Hans Sacklén (2006). "Low-inflation Targeting and Long-run Unemployment," Scandinavian Journal of Economics, 108: 397-418.

Messina, Julián \& Cláudia Filipa Duarte \& Mario Izquierdo \& Philip Du Caju \& Niels Lynggård Hansen, (2010). "The Incidence of Nominal and Real Wage Rigidity: An Individual-Based Sectoral Approach," Journal of the European Economic Association, MIT Press, vol. 8(2-3), pages 487-496, 04-05.

Phelps, Edmund S. (1994). Structural Slumps, The Modern Equilibrium Theory of Unemployment, Interest and Assets, Cambridge MA: Harvard University Press.

Phillips, Arthur W. H. (1958). "The relation between Unemployment and the Rate of Change of Money Wages in the United Kingdom, 1861-1957," Economica, 25 (100), 283-299.

Pissarides, Christopher A. \& Giovanna Vallanti, (2007). "The Impact Of Tfp Growth On Steady-State Unemployment," International Economic Review, Department of Economics, University of Pennsylvania and Osaka University Institute of Social and Economic Research Association, vol. 48(2), pages 607-640, 05.

Shimer, Robert (2005). "The Cyclical Behavior of Equilibrium Unemployment and Vacancies," American Economic Review 95(1), 25-49.

Shimer, Robert, (2012). "Wage rigidities and jobless recoveries," Journal of Monetary Economics, Elsevier, vol. 59(S), pages S65-S77.

Staiger, Douglas \& James H. Stock \& Mark W. Watson, (2001). "Prices, Wages and the U.S. NAIRU in the 1990s," NBER Working Papers 8320, National Bureau of Economic Research, Inc. 
Stokey, Nancy L. (2006), Brownian Models in Economics, mimeo, University of Chicago.

Stock, James H. \& Mark W. Watson, (2003). "Has the Business Cycle Changed and Why?," NBER Chapters, in: NBER Macroeconomics Annual 2002, Volume 17, pages 159-230 National Bureau of Economic Research, Inc.

Svensson, Lars E O. (2015). "The Possible Unemployment Cost of Average Inflation below a Credible Target." American Economic Journal: Macroeconomics, 7(1): 258-96.

Tobin, James (1972), "Inflation and Unemployment," American Economic Review, $62,1-18$. 


\section{Appendix}

\section{A.1 Wage decision for forward-looking workers}

In this appendix, the wage decision problem is solved for not-myopic households, that is for households that are aware of the lower bound on nominal wage changes, i.e. $d W_{t} \geqslant 0$. In this case, each $j$ household chooses a sequence of optimal nominal wages, among the ones belonging to the space $\Omega$ of non-decreasing stochastic processes $\left\{W_{t}(j)\right\}$. In details each $j$ household maximizes the following objective function,

$$
E_{t}\left\{\int_{t}^{\infty} e^{-\rho\left(t-t_{0}\right)} \pi\left(W_{t}(j), W_{t}, P_{t}, A_{t}\right) d t\right\}
$$

where the surplus $\pi\left(W_{t}(j), W_{t}, P_{t}, A_{t}\right)$ for period $t$ can be defined as $\pi\left(W_{t}(j), W_{t}, P_{t}, A_{t}\right) \equiv$ $\left(\frac{1}{P_{t} C_{t}}\right) W_{t}(j) l_{t}(j)-\left(\frac{l_{t}(j)^{1+\eta}}{1+\eta}\right) \cdot{ }^{24}$ Objective function $(23)$ is concave over a convex set. The set $\Omega$ is convex because for any $x \in \Omega$ and $y \in \Omega$ then $\tau x+(1-\tau) y \in \Omega$ for each $\tau \in[0,1]$. Objective function is concave in $W_{t}(j)$ because it is an integral of functions $\pi(\cdot)$ that are concave in the first-argument. The value function $V(\cdot)$ associated to household problem is given by

$$
V\left(W_{t}(j), W_{t}, P_{t}, A_{t}\right)=\max _{\left\{W_{\tau}(j)\right\}_{\tau=0}^{\infty} \in \Omega} E_{t}\left\{\int_{t}^{\infty} e^{-\rho\left(t-t_{0}\right)} \pi\left(W_{t}(j), W_{t}, P_{t}, A_{t}\right) d t\right\} .
$$

The related Bellman equation for the wage-setter problem can be written as

$$
\rho V\left(W_{t}(j), W_{t}, P_{t}, A_{t}\right) d t=\max _{d W_{t}(j)} \pi\left(W_{t}(j), W_{t}, P_{t}, A_{t}\right) d t+E_{t}\left[d V\left(W_{t}(j), W_{t}, P_{t}, A_{t}\right)\right]
$$

subject to $d W_{t}(j) \geqslant 0$. Or,

$$
\max _{d W_{t}(j)} \pi\left(W_{t}(j), W_{t}, P_{t}, A_{t}\right) d t+E_{t}\left[d V\left(W_{t}(j), W_{t}, P_{t}, A_{t}\right)\right]-\lambda_{t}\left(-d W_{t}(j)\right)
$$

where $\lambda_{t}$ is the multiplier associated to the inequality constraint $d W_{t}(j) \geqslant 0$. The first order condition gives

$$
V_{W(j)}\left(W_{t}(j), W_{t}, P_{t}, A_{t}\right)+\lambda_{t}=0,
$$

\footnotetext{
${ }^{24}$ Using both aggregate labor demand (5) and individul labor demand (7), the household surplus becomes

$$
\pi\left(W_{t}(j), W_{t}, P_{t}, A_{t}\right)=\alpha\left(\frac{W_{t}(j)}{W_{t}}\right)^{1-\theta_{\omega}}-\frac{1}{1+\eta}\left(\left(\frac{W_{t}(j)}{W_{t}}\right)^{-\theta_{\omega}}\left(\frac{\alpha P_{t} A_{t}}{W_{t}}\right)^{\frac{1}{1-\alpha}}\right)^{1+\eta}
$$
}


with $\lambda_{t}\left(-d W_{t}(j)\right)=0$ as complementary slackness condition. The first term on the LHS of (27) comes from the expected value of $d V\left(W_{t}(j), W_{t}, P_{t}, A_{t}\right)$. Indeed, from the Ito's lemma it holds,

$$
\begin{aligned}
E_{t}\left[d V\left(W_{t}(j), W_{t}, P_{t}, A_{t}\right)\right]= & E_{t}\left[V_{W_{t}(j)}\left(W_{t}(j), W_{t}, P_{t}, A_{t}\right) d W_{t}(j)\right]+ \\
& +E_{t}\left[V_{W}\left(W_{t}(j), W_{t}, P_{t}, A_{t}\right) d W_{t}\right]+ \\
& +\frac{1}{2} E_{t}\left[V_{W W}\left(W_{t}(j), W_{t}, P_{t}, A_{t}\right) d W_{t}^{2}\right]+ \\
& +E_{t}\left[V_{P}\left(W_{t}(j), W_{t}, P_{t}, A_{t}\right) d P_{t}\right]+ \\
& +\frac{1}{2} E_{t}\left[V_{P P}\left(W_{t}(j), W_{t}, P_{t}, A_{t}\right) d P_{t}^{2}\right]+ \\
& +E_{t}\left[V_{A}\left(W_{t}(j), W_{t}, P_{t}, A_{t}\right) d A_{t}\right]+ \\
& +\frac{1}{2} E_{t}\left[V_{A A}\left(W_{t}(j), W_{t}, P_{t}, A_{t}\right) d A_{t}^{2}\right]+ \\
& +E_{t}\left[V_{W P}\left(W_{t}(j), W_{t}, P_{t}, A_{t}\right) d W_{t} d P_{t}\right]+ \\
& +E_{t}\left[V_{W A}\left(W_{t}(j), W_{t}, P_{t}, A_{t}\right) d W_{t} d A_{t}\right],
\end{aligned}
$$

where to obtain (28) it is considered that $d W_{t}(j)$ has finite variance, that is it holds $d W_{t}(j)^{2}=d W_{t}(j) d W_{t}=d W_{t}(j) d P_{t}=d W_{t}(j) d A_{t}=0$. From (2) and (3), the processes that lead dynamics of price and productivity levels are,

$$
\begin{aligned}
d P_{t} & =\left(\mu+\frac{\sigma_{P}^{2}}{2}\right) P_{t} d t+\sigma_{P} P_{t} d B_{P, t}, \\
\left(d P_{t}\right)^{2} & =\sigma_{P}^{2} P_{t}^{2} d t
\end{aligned}
$$

and

$$
\begin{aligned}
d A_{t} & =\left(g+\frac{\sigma_{A}^{2}}{2}\right) A_{t} d t+\sigma_{A} A_{t} d B_{A, t} \\
\left(d A_{t}\right)^{2} & =\sigma_{A}^{2} A_{t}^{2} d t
\end{aligned}
$$

The two processes are independent, thereby $E_{t}\left[d P_{t} d A_{t}\right]=0$. Plugging (29)-(32) into (28), it becomes

$$
\begin{aligned}
E_{t}\left[d V\left(W_{t}(j), W_{t}, P_{t}, A_{t}\right)\right]= & E_{t}\left[V_{W_{t}(j)}(\cdot) d W_{t}(j)\right]+ \\
& +E_{t}\left[V_{W}(\cdot) d W_{t}\right]+\frac{1}{2} E_{t}\left[V_{W W}(\cdot) d W_{t}^{2}\right]+ \\
& +V_{P}(\cdot)\left(\mu+\frac{\sigma_{P}^{2}}{2}\right) P_{t} d t+\frac{1}{2} V_{P P}(\cdot) \sigma_{P}^{2} P_{t}^{2} d t+ \\
& +V_{A}(\cdot)\left(g+\frac{\sigma_{A}^{2}}{2}\right) A_{t} d t+\frac{1}{2} V_{A A}(\cdot) \sigma_{A}^{2} A_{t}^{2} d t+ \\
& +E_{t}\left[V_{W P}(\cdot) d W_{t} d P_{t}\right]+E_{t}\left[V_{W A}(\cdot) d W_{t} d A_{t}\right] .
\end{aligned}
$$


Finally, taking the first derivative of (33) with respect to $d W_{t}(j)$, it is gives the first term on the LHS of (27).

Importantly equation (27) and complementary slackness condition ensure the following two possible scenarios,

$$
\begin{aligned}
& \text { if } \quad d W_{t}(j)>0 \Longrightarrow V_{W(j)}\left(W_{t}(j), W_{t}, P_{t}, A_{t}\right)=0, \\
& \text { if } \quad d W_{t}(j)=0 \Longrightarrow V_{W(j)}\left(W_{t}(j), W_{t}, P_{t}, A_{t}\right) \leq 0 .
\end{aligned}
$$

Focusing only on the case with growing nominal wages, i.e. $d W_{t}(j)>0$, the first term on the RHS of (33) cancels out and the Bellman equation (25) becomes,

$$
\begin{aligned}
\rho V\left(W_{t}(j), W_{t}, P_{t}, A_{t}\right) d t= & \pi(\cdot) d t+ \\
& +E_{t}\left[V_{W}(\cdot) d W_{t}\right]+\frac{1}{2} E_{t}\left[V_{W W}(\cdot) d W_{t}^{2}\right]+ \\
& +\left[V_{P}(\cdot)\left(\mu+\frac{\sigma_{P}^{2}}{2}\right) P_{t}+\frac{1}{2} V_{P P}(\cdot) \sigma_{P}^{2} P_{t}^{2}\right] d t+ \\
& +\left[V_{A}(\cdot)\left(g+\frac{\sigma_{A}^{2}}{2}\right) A_{t}+\frac{1}{2} V_{A A}(\cdot) \sigma_{A}^{2} A_{t}^{2}\right] d t \\
& +E_{t}\left[V_{W P}(\cdot) d W_{t} d P_{t}\right]+E_{t}\left[V_{W A}(\cdot) d W_{t} d A_{t}\right] .
\end{aligned}
$$

Differentiating then both sides of $(36)$ with respect to $W_{t}(j)$, it holds

$$
\begin{aligned}
\rho V\left(W_{t}(j), W_{t}, P_{t}, A_{t}\right) d t= & \pi_{W(j)}(\cdot) d t+E_{t}\left[V_{W(j) W} d W_{t}\right]+\frac{1}{2} E_{t}\left[V_{W(j) W W} d W_{t}^{2}\right]+ \\
& +\left[V_{W(j) P}(\cdot)\left(\mu+\frac{\sigma_{P}^{2}}{2}\right) P_{t}+\frac{1}{2} V_{W(j) P P}(\cdot) \sigma_{P}^{2} P_{t}^{2}\right] d t+ \\
& +\left[V_{W(j) A}(\cdot)\left(g+\frac{\sigma_{A}^{2}}{2}\right) A_{t}+\frac{1}{2} V_{W(j) A A}(\cdot) \sigma_{A}^{2} A_{t}^{2}\right] d t \\
& +E\left[V_{W(j) W P} d W_{t} d P_{t}\right]+E\left[V_{W(j) W A} d W_{t} d A_{t}\right] .
\end{aligned}
$$

Since the objective is concave and the set of constraints is convex, the optimal choice for $W_{t}(j)$ is unique. It follows that $W_{t}(j)=W_{t}$ for each $j$. Also $W_{t}$ has a finite variance, so that $d W_{t}^{2}=d W_{t} d P_{t}=d W_{t} d A_{t}=0$. Moreover, super-contact conditions ${ }^{25}$ require that when $d W_{t}(j)>0$, the following holds

$$
\begin{aligned}
V_{W_{t}(j) W_{t}(j)}\left(W_{t}, P_{t}, A_{t}\right) & =0 \\
V_{W_{t}(j) W}\left(W_{t}, P_{t}, A_{t}\right) & =0 \\
V_{W_{t}(j) P}\left(W_{t}, P_{t}, A_{t}\right) & =0 \\
V_{W_{t}(j) A}\left(W_{t}, P_{t}, A_{t}\right) & =0 .
\end{aligned}
$$

\footnotetext{
${ }^{25}$ See Dixit (1991) and Dumas (1991)
} 
Equation (37) reduces then to

$$
\begin{aligned}
\rho V_{W}(\cdot)= & \pi_{W}(\cdot)+ \\
& +\left[V_{W P}(\cdot)\left(\mu+\frac{\sigma_{P}^{2}}{2}\right) P_{t}+\frac{1}{2} V_{W P P}(\cdot) \sigma_{P}^{2} P_{t}^{2}\right]+ \\
& +\left[V_{W A}(\cdot)\left(g+\frac{\sigma_{A}^{2}}{2}\right) A_{t}+\frac{1}{2} V_{W A A}(\cdot) \sigma_{A}^{2} A_{t}^{2}\right],
\end{aligned}
$$

where $\pi_{W}\left(W_{t}, P_{t}, A_{t}\right)=\left(\frac{1-\theta_{\omega}}{W_{t}}\right)\left[\alpha-\mu_{\omega}\left(\frac{\alpha P_{t} A_{t}}{W_{t}}\right)^{\frac{1+\eta}{1-\alpha}}\right]$. Defining $V_{W}(\cdot) \equiv v(\cdot)$, can be rewritten as a differential equation of second order,

$$
\begin{aligned}
& -\frac{1}{2} v_{P P}\left(W_{t}, P_{t}, A_{t}\right) \sigma_{P}^{2} P_{t}^{2} W_{t}-\frac{1}{2} v_{A A}\left(W_{t}, P_{t}, A_{t}\right) \sigma_{A}^{2} A_{t}^{2} W_{t} \\
& -v_{P}\left(W_{t}, P_{t}, A_{t}\right)\left(\mu+\frac{\sigma_{P}^{2}}{2}\right) P_{t} W_{t}-v_{A}\left(W_{t}, P_{t}, A_{t}\right)\left(g+\frac{\sigma_{A}^{2}}{2}\right) A_{t} W_{t} \\
& +\rho v\left(W_{t}, P_{t}, A_{t}\right) W_{t} \\
= & \left(1-\theta_{\omega}\right)\left[\alpha-\mu_{\omega}\left(\frac{\alpha P_{t} A_{t}}{W_{t}}\right)^{\frac{1+\eta}{1-\alpha}}\right] .
\end{aligned}
$$

Now let's assume that $v\left(W_{t}, P_{t}, A_{t}\right) W_{t}=v\left(\tilde{\Gamma}_{t}\right)$ with $\tilde{\Gamma}_{t} \equiv \frac{P_{t} A_{t}}{W_{t}} \cdot{ }^{26}$ Equation (43)

$$
\begin{aligned}
& { }^{26} \text { Indeed, derivative terms of (43) become } \\
& \begin{aligned}
v_{P} & =\frac{\partial}{\partial P_{t}} v\left(W_{t}, P_{t}, A_{t}\right)=\frac{\partial}{\partial P_{t}}\left[v\left(\frac{P_{t} A_{t}}{W_{t}}\right) \frac{1}{W_{t}}\right] \\
& =\frac{\partial}{\partial \tilde{\Gamma}_{t}} v\left(\tilde{\Gamma}_{t}\right) \frac{A_{t}}{W_{t}^{2}}=v_{\Gamma} \frac{A_{t}}{W_{t}^{2}}
\end{aligned} \\
& v_{A}=\frac{\partial}{\partial A_{t}} v\left(W_{t}, P_{t}, A_{t}\right)=\frac{\partial}{\partial A_{t}}\left[v\left(\frac{P_{t} A_{t}}{W_{t}}\right) \frac{1}{W_{t}}\right] \\
& =\frac{\partial}{\partial \tilde{\Gamma}_{t}} v\left(\tilde{\Gamma}_{t}\right) \frac{P_{t}}{W_{t}^{2}}=v_{\Gamma} \frac{P_{t}}{W_{t}^{2}} \\
& v_{P P}=\frac{\partial^{2}}{\partial P_{t}^{2}} v\left(W_{t}, P_{t}, A_{t}\right)=\frac{\partial}{\partial P_{t}^{2}}\left[v\left(\frac{P_{t} A_{t}}{W_{t}}\right) \frac{1}{W_{t}}\right] \\
& =\frac{\partial}{\partial \tilde{\Gamma}_{t}}\left(\frac{\partial}{\partial \tilde{\Gamma}_{t}} v\left(\tilde{\Gamma}_{t}\right) \frac{A_{t}}{W_{t}}\right) \frac{A_{t}}{W_{t}^{2}}=v_{\Gamma \Gamma} \frac{A_{t}^{2}}{W_{t}^{3}} ; \\
& v_{A A}=\frac{\partial^{2}}{\partial A_{t}^{2}} v\left(W_{t}, P_{t}, A_{t}\right)=\frac{\partial}{\partial A_{t}^{2}}\left[v\left(\frac{P_{t} A_{t}}{W_{t}}\right) \frac{1}{W_{t}}\right] \\
& =\frac{\partial}{\partial \tilde{\Gamma}_{t}}\left(\frac{\partial}{\partial \tilde{\Gamma}_{t}} v\left(\tilde{\Gamma}_{t}\right) \frac{P_{t}}{W_{t}}\right) \frac{P_{t}}{W_{t}^{2}}=v_{\Gamma \Gamma} \frac{P_{t}^{2}}{W_{t}^{3}} .
\end{aligned}
$$


can be read as,

$$
\begin{aligned}
& -\left(\frac{\sigma_{P}^{2}}{2}+\frac{\sigma_{A}^{2}}{2}\right) v_{\Gamma \Gamma} \tilde{\Gamma}_{t}^{2}-\left(\mu+g+\frac{\sigma_{P}^{2}}{2}+\frac{\sigma_{A}^{2}}{2}\right) v_{\Gamma} \tilde{\Gamma}_{t}+\rho v \\
= & \left(1-\theta_{\omega}\right)\left[\alpha-\mu_{\omega}\left(\alpha \tilde{\Gamma}_{t}\right)^{\frac{1+\eta}{1-\alpha}}\right] .
\end{aligned}
$$

Equation (44) is a Cauchy-Euler equation, which through a change of variables can be transformed into a constant-coefficient equation. Defining indeed $\widetilde{\Gamma}_{t} \equiv e^{x_{t}}$, it is true that

$$
\frac{\partial}{\partial x_{t}} v\left(\tilde{\Gamma}_{t}\right)=\frac{\partial v\left(\tilde{\Gamma}_{t}\right)}{\partial \tilde{\Gamma}_{t}} e^{x_{t}}=v_{\Gamma} e^{x_{t}}=v_{\Gamma} \tilde{\Gamma}_{t}
$$

and

$$
\begin{aligned}
\frac{\partial^{2}}{\partial x_{t}^{2}} v\left(\tilde{\Gamma}_{t}\right) & =\frac{\partial^{2} v\left(\tilde{\Gamma}_{t}\right)}{\partial \tilde{\Gamma}_{t}^{2}} e^{2 x_{t}}+v_{\Gamma} \frac{\partial}{\partial x_{t}} e^{x_{t}} \\
& =v_{\Gamma \Gamma} e^{2 x_{t}}+v_{\Gamma} e^{x_{t}}=v_{\Gamma \Gamma} \tilde{\Gamma}_{t}^{2}+v_{\Gamma} \tilde{\Gamma}_{t}
\end{aligned}
$$

Plugging (45) and (46) into Equation (44), it boils down to,

$$
\begin{aligned}
& -\left(\frac{\sigma_{P}^{2}+\sigma_{A}^{2}}{2}\right) \frac{\partial^{2}}{\partial x_{t}^{2}} v\left(\tilde{\Gamma}_{t}\right)-(\mu+g) \frac{\partial}{\partial x_{t}} v\left(\tilde{\Gamma}_{t}\right)+\rho v\left(\tilde{\Gamma}_{t}\right) \\
= & \left(1-\theta_{\omega}\right) \frac{\alpha}{\mu_{p}}-\theta_{\omega}\left(\frac{\alpha}{\mu_{p}} \tilde{\Gamma}_{t}\right)^{\frac{1+\eta}{1-\alpha}} .
\end{aligned}
$$

The LHS of (47) is the characteristic equation, which can be solved by finding the two roots $\iota_{1,2}$,

$$
\iota_{1,2}=\frac{1}{\sigma_{P}^{2}+\sigma_{A}^{2}}\left(-(\mu+g) \pm \sqrt{(\mu+g)^{2}+2 \rho\left(\sigma_{P}^{2}+\sigma_{A}^{2}\right)}\right) .
$$

Given that $v\left(W_{t}, P_{t}, A_{t}\right)=\frac{v\left(\tilde{\Gamma}_{t}\right)}{W_{t}}$, the complementary solution in terms of $v(\cdot)$ has the following form,

$$
v^{c}\left(W_{t}, P_{t}, A_{t}\right)=\left(\kappa_{1}\left|\frac{P_{t} A_{t}}{W_{t}}\right|^{\iota_{1}}+\kappa_{2}\left|\frac{P_{t} A_{t}}{W_{t}}\right|^{\iota_{2}}\right) W_{t}^{-1} .
$$


As regards the particular solution, it is used the method of undetermined coefficients. Given the RHS of (47), a possible solution might assume the form $v^{p}=A+B \tilde{\Gamma}_{t}^{\frac{1+\eta}{1-\alpha}}$. Constant $A$ and $B$ are then determined as,

$$
\begin{aligned}
A & =\left(1-\theta_{\omega}\right) \frac{\alpha}{\rho \mu_{p}} \\
B & =\theta_{\omega}\left(\frac{\alpha}{\mu_{p}}\right)^{\frac{1+\eta}{1-\alpha}}\left(\left(\frac{\sigma_{P}^{2}}{2}+\frac{\sigma_{A}^{2}}{2}\right)\left(\frac{1+\eta}{1-\alpha}\right)^{2}+(\mu+g)\left(\frac{1+\eta}{1-\alpha}\right)-\rho\right)^{-1} .
\end{aligned}
$$

The particular solution in terms of $v(\cdot)$ can then be written as,

$$
\begin{aligned}
v^{p}\left(W_{t}, P_{t}, A_{t}\right)= & \left(1-\theta_{\omega}\right) \frac{\alpha}{\rho \mu_{p}} \frac{1}{W_{t}}+ \\
& -\frac{\theta_{\omega}}{W_{t}}\left(\rho-\left(\frac{\sigma_{P}^{2}}{2}+\frac{\sigma_{A}^{2}}{2}\right)\left(\frac{1+\eta}{1-\alpha}\right)^{2}-(\mu+g)\left(\frac{1+\eta}{1-\alpha}\right)\right)^{-1}\left(\frac{\alpha}{\mu_{p}} \frac{P_{t} A_{t}}{W_{t}}\right)^{\frac{1+\eta}{1-\alpha}}(52)
\end{aligned}
$$

Since when $W \rightarrow \infty$ and/or $P_{t} A_{t} \rightarrow 0$, the length of time until the next wage adjustment can be made arbitrarily long with probability arbitrarily close to one, ${ }^{27}$ then it should be the case that

$$
\begin{aligned}
\lim _{W \rightarrow \infty}\left[v\left(W_{t}, P_{t}, A_{t}\right)-v^{p}\left(W_{t}, P_{t}, A_{t}\right)\right] & =0, \\
\lim _{P_{t} A_{t} \rightarrow 0}\left[v\left(W_{t}, P_{t}, A_{t}\right)-v^{p}\left(W_{t}, P_{t}, A_{t}\right)\right] & =0,
\end{aligned}
$$

which both require that $\iota$ should be positive. The general solution is finally obtained by the sum of particular solution (52) and complementary one (49),

$$
v\left(W_{t}, P_{t}, A_{t}\right)=\left(1-\theta_{\omega}\right) \frac{\alpha}{\rho W_{t}}-\frac{\theta_{\omega}}{W_{t}} \Delta\left(\alpha \frac{P_{t} A_{t}}{W_{t}}\right)^{\frac{1+\eta}{1-\alpha}}+\kappa\left(\frac{P_{t} A_{t}}{W_{t}}\right)^{\iota} \frac{1}{W_{t}}
$$

where $\Delta$ is defined as $\Delta=\left(\rho-\left(\frac{\sigma_{P}^{2}}{2}+\frac{\sigma_{A}^{2}}{2}\right)\left(\frac{1+\eta}{1-\alpha}\right)^{2}-(\mu+g)\left(\frac{1+\eta}{1-\alpha}\right)\right)^{-1}$, whereas $\kappa$ is a constant to be determined.

To find explicitly the optimal wage $W_{t}$, it necessary to define a function $W\left(P_{t}, A_{t}\right)$ such that if nominal wages are constant, i.e. $d W_{t}(j)=0$, it holds $v\left(W\left(P_{t}, A_{t}\right), P_{t}, A_{t}\right) \leq$ 0 , while if they are increasing, i.e. $d W_{t}(j)>0$, the followings are verified,

$$
\begin{aligned}
v\left(W\left(P_{t}, A_{t}\right), P_{t}, A_{t}\right) & =0 \\
v_{W}\left(W\left(P_{t}, A_{t}\right), P_{t}, A_{t}\right) & =0 \\
v_{P}\left(W\left(P_{t}, A_{t}\right), P_{t}, A_{t}\right) & =0 \\
v_{A}\left(W\left(P_{t}, A_{t}\right), P_{t}, A_{t}\right) & =0 .
\end{aligned}
$$

\footnotetext{
${ }^{27}$ See Stokey (2006).
} 
Evaluating then the general solution at $W\left(P_{t}, A_{t}\right)$, it holds

$$
\left(1-\theta_{\omega}\right) \frac{\alpha}{\rho}-\left(1-\theta_{\omega}\right) \Delta \mu_{\omega}\left(\alpha \frac{P_{t} A_{t}}{W_{t}\left(P_{t}, A_{t}\right)}\right)^{\frac{1+\eta}{1-\alpha}}+\kappa\left(\frac{P_{t} A_{t}}{W_{t}\left(P_{t}, A_{t}\right)}\right)^{\iota}=0 .
$$

From (56), it holds

$$
-\left(1-\theta_{\omega}\right) \frac{\alpha}{\rho}+\left(\frac{2+\eta-\alpha}{1-\alpha}\right)\left(1-\theta_{\omega}\right) \Delta \mu_{\omega}\left(\alpha \frac{P_{t} A_{t}}{W_{t}\left(P_{t}, A_{t}\right)}\right)^{\frac{1+\eta}{1-\alpha}}+-(1+\iota) \kappa\left(\frac{P_{t} A_{t}}{W_{t}\left(P_{t}, A_{t}\right)}\right)^{\iota}=0 .
$$

From (57), it holds

$$
\left(\frac{1+\eta}{1-\alpha}\right)\left(\frac{1-\theta_{\omega}}{\iota}\right) \Delta \mu_{\omega}\left(\frac{\alpha}{\mu_{p}}\right)^{\frac{1+\eta}{1-\alpha}}\left(\frac{P_{t} A_{t}}{W_{t}\left(P_{t}, A_{t}\right)}\right)^{\frac{1+\eta}{1-\alpha}}=\kappa\left(\frac{P_{t} A_{t}}{W_{t}\left(P_{t}, A_{t}\right)}\right)^{\iota} .
$$

From (58), it holds

$$
\left(\frac{1+\eta}{1-\alpha}\right)\left(\frac{1-\theta_{\omega}}{\iota}\right) \Delta \mu_{\omega}\left(\frac{\alpha}{\mu_{p}}\right)^{\frac{1+\eta}{1-\alpha}}\left(\frac{P_{t} A_{t}}{W_{t}\left(P_{t}, A_{t}\right)}\right)^{\frac{1+\eta}{1-\alpha}}=\kappa\left(\frac{P_{t} A_{t}}{W_{t}\left(P_{t}, A_{t}\right)}\right)^{\iota} .
$$

Equations (61) and (62) are equal, while from equations (59) and (60) it is determined the constant $\kappa$

$$
\begin{aligned}
\kappa\left(\frac{P_{t} A_{t}}{W_{t}\left(P_{t}, A_{t}\right)}\right)^{\iota}= & -\left(\frac{2}{2+\iota}\right)\left(\left(1-\theta_{\omega}\right) \frac{\alpha}{\rho}\right)+ \\
& +\left(\frac{3+\eta-2 \alpha}{1-\alpha}\right)\left(\frac{1-\theta_{\omega}}{2+\iota}\right) \Delta \mu_{\omega} \alpha^{\frac{1+\eta}{1-\alpha}}\left(\frac{P_{t} A_{t}}{W_{t}\left(P_{t}, A_{t}\right)}\right)^{\frac{1+\eta}{1-\alpha}} .
\end{aligned}
$$

Plugging (63) into (61) or (62) and then substituting $\Delta \equiv\left(\rho-\left(\frac{\sigma_{P}^{2}+\sigma_{A}^{2}}{2}\right)\left(\frac{1+\eta}{1-\alpha}\right)^{2}-(\mu+g)\left(\frac{1+\eta}{1-\alpha}\right)\right)^{-1}$ and $\rho=\left(\frac{\sigma_{P}^{2}+\sigma_{A}^{2}}{2}\right) \iota^{2}+(\mu+g) \iota$, the optimal wage for forward-looking workers is finally determined as

$$
W_{t}\left(P_{t}, A_{t}\right)=\left(-\frac{\rho}{\iota(1-\alpha)} \frac{1+\eta-\iota(1-\alpha)}{\rho-\left(\frac{\sigma_{P}^{2}+\sigma_{A}^{2}}{2}\right)\left(\frac{1+\eta}{1-\alpha}\right)^{2}-(\mu+g)\left(\frac{1+\eta}{1-\alpha}\right)}\right)^{\frac{1-\alpha}{1+\eta}} \alpha^{\frac{\alpha+\eta}{1+\eta}} \mu_{\omega}^{\frac{1-\alpha}{1+\eta}} P_{t} A_{t}
$$

or alternatively,

$$
W_{t}\left(P_{t}, A_{t}\right) \equiv \tilde{W}_{t}^{*}=c\left(\vartheta, \tilde{\sigma}^{2}, \alpha, \eta, \iota\right) W_{t}^{*},
$$

where

$$
c\left(\vartheta, \tilde{\sigma}^{22}, \alpha, \eta, \iota\right) \equiv\left(\frac{\frac{\tilde{\sigma}^{2}}{2} \iota+\vartheta}{\frac{\tilde{\sigma}^{22}}{2} \iota+\vartheta+\frac{\tilde{\sigma}^{22}}{2}\left(\frac{1+\eta}{1-\alpha}\right)}\right)^{\frac{1-\alpha}{1+\eta}}
$$




$$
\vartheta \equiv \mu+g, \quad \tilde{\sigma}^{2} \equiv \sigma_{P}^{2}+\sigma_{A}^{2}
$$

and

$$
W_{t}^{*}=\alpha^{\frac{\alpha+\eta}{1+\eta}} \mu_{\omega}^{\frac{1-\alpha}{1+\eta}} P_{t} A_{t} .
$$

The optimal nominal wage for non-myopic workers is proportional to the nominal wage $W_{t}^{*}$ prevailing without rigidity. The latter can be conveniently recovered by equating aggregate labor demand (5) with the labor supply (11) provided by myopic workers in case of positive variations of nominal wages, i.e. $d W_{t}>0$. Since $c\left(\vartheta, \tilde{\sigma}^{2}, \alpha, \eta, \iota\right) \in[0,1]$, optimal wage $\tilde{W}_{t}^{*}$, or desired wage following Benigno and Ricci (2010), for workers aware of the non-negative bound on wage changes is lower than the flexible wage $W_{t}^{*}$. Intuitively, forward-looking workers choose to minimize the increments of nominal wages in order to reduce the probability that the lower bound binds in the future. The lower is the growth in nominal wages, the lower is the probability that the constraint is hit for a given contraction in price or productivity level, and the lower is the probability that unemployment overshoot its natural level. Like in the case of myopic workers, the dynamics of optimal wage continues to be driven by the underlying processes of price and productivity level. Unemployment as well, whenever nominal wages are stuck to previous period level, continues to follow a geometric Brownian motion with drift and volatility coefficients given by the combination of inflation and productivity growth processes. The unemployment value prevailing when nominal wage adjust upward, i.e. the natural level of unemployment, is however lower than in the case of myopic workers. To prove that, the labor demand schedule (5) is firstly substituted in (65), in order to detect the employment level prevailing when $d W_{t}>0$,

$$
\alpha P_{t} A_{t} L_{t}^{\alpha-1}=c \alpha^{\frac{\alpha+\eta}{1+\eta}} \mu_{\omega}^{\frac{1-\alpha}{1+\eta}} P_{t} A_{t}
$$

or,

$$
\tilde{L}_{t}^{*}=c^{-\frac{1}{1-\alpha}} \alpha^{\frac{1}{1+\eta}} \mu_{\omega}^{-\frac{1}{1+\eta}}
$$

Analogously, the employment level prevailing with myopic workers when $d W_{t}>0$, is recovered by equating the labor demand schedule (5) to the labor supply schedule (11) evaluated when goods market clears,

$$
\alpha P_{t} A_{t} L_{t}^{\alpha-1}=\mu_{\omega} P_{t} A_{t} L_{t}^{\alpha+\eta}
$$

or,

$$
L_{t}^{*}=\alpha^{\frac{1}{1+\eta}} \mu_{\omega}^{-\frac{1}{1+\eta}} .
$$

Combining then (66) with (67), it holds

$$
\tilde{L}_{t}^{*}=c^{-\frac{1}{1-\alpha}} L_{t}^{*}
$$


Plugging the labor supply schedule (11) and the equation (68) into (65), the desired wage can be obtained as,

$$
\begin{aligned}
\tilde{W}_{t}^{*} & =c W_{t}^{*} \\
& =c \mu_{\omega} P_{t} A_{t}\left(L_{t}^{*}\right)^{\alpha+\eta} \\
& =c^{1+\frac{\eta}{1-\alpha}} \mu_{\omega} P_{t} C_{t}\left(c^{-\frac{1}{1-\alpha}} L_{t}^{*}\right)^{\eta}
\end{aligned}
$$

or

$$
\frac{\tilde{W}_{t}^{*}}{P_{t} C_{t}}=c^{1+\frac{\eta}{1-\alpha}} \mu_{\omega}\left(\tilde{L}_{t}^{*}\right)^{\eta}
$$

Therefore the notional labor supply (15) can be then rewritten as

$$
\ln \left(L_{t}^{n}\right)=\frac{1}{\eta}\left(1+\frac{\eta}{1-\alpha}\right) \ln c+\frac{1}{\eta} \ln \mu_{\omega}+\ln \left(\tilde{L}_{t}^{*}\right) .
$$

To recover the unemployment rate defined as in Gali $(2011)$, i.e. $u_{t} \equiv \ln \left(L_{t}^{n}\right)-$ $\ln \left(L_{t}^{d}\right)$, the labor demand $\ln L_{t}^{d}$ is subtracted from the both sides of (69)

$$
u_{t}=\frac{1}{\eta}\left(\frac{1+\eta-\alpha}{1-\alpha}\right) \ln c+\frac{1}{\eta} \ln \mu_{\omega}+\ln \left(\tilde{L}_{t}^{*}\right)-\ln \left(L_{t}^{d}\right)
$$

Whenever nominal wage is equal to the optimal level, $W_{t}=\tilde{W}_{t}^{*}$, labor market clears, i.e. $\ln \left(\tilde{L}_{t}^{*}\right)=\ln \left(L_{t}^{d}\right)$, and unemployment is equal to its natural level. However, the natural level of employment level prevailing with forward-looking workers, is lower than the corresponding one with myopic workers, because $\eta>1, \alpha<1$ and $c \in[0,1]$. 


\section{Tables}

\begin{tabular}{|c|c|c|c|c|c|c|c|}
\hline Regressors & (1) & (2) & (3) & (4) & (5) & (6) & (7) \\
\hline$\triangle \mathrm{CPI} \mathrm{m}$ & $-0,0909 * * *$ & & & & $-0,0876^{* * *}$ & & \\
\hline t-statistics & $-7,530$ & & & & $-6,354$ & & \\
\hline$\Delta$ CPI_std & $0,0443 * * *$ & & & & $0,1094 * \pi *$ & & \\
\hline t-statistics & 4,613 & & & & 3,219 & & \\
\hline$\triangle \mathrm{DEF} \_\mathrm{m}$ & & $-0,0857^{* * *}$ & & & & $-0,0937 \div * \pi$ & \\
\hline t-statistics & & $-6,123$ & & & & $-6,661$ & \\
\hline$\triangle \mathrm{DEF} \_$std & & $0,0756 \approx$ & & & & $0,0953^{* *}$ & \\
\hline t-statistics & & 2,010 & & & & 2,379 & \\
\hline$\Delta \mathrm{NW} \_\mathrm{m}$ & & & $-0,3252 \ldots \pi$ & & & & $-0,2230$ 추 \\
\hline t-statistics & & & $-6,529$ & & & & $-4,398$ \\
\hline $\begin{array}{l}\Delta \mathrm{NW}_{\text {_std }} \text { t-statistics } \\
\text { to }\end{array}$ & & & $\begin{array}{c}-0,1348 * * \\
-2,078\end{array}$ & & & & $\begin{array}{l}-0,1131 \\
-1,566\end{array}$ \\
\hline$\Delta$ LabProd_m & & & & $-0,1187$ & $-0,2215^{* \cdots *}$ & $-0,1868^{* *}$ & $-0,0582$ \\
\hline t-statistics & & & & $-1,454$ & $-2,744$ & $-2,315$ & $-0,628$ \\
\hline$\underset{\text { t-statistics }}{\Delta \text { LabProd_std }}$ & & & & 0,0798 & $0,1427 *$ & $0,1416^{*}$ & $0,2101 * *$ \\
\hline & & & & 1,115 & 1,938 & 1,963 & 2,463 \\
\hline Observations & 1044 & 899 & 821 & 819 & 816 & 815 & 765 \\
\hline LSDV R-squared & 0,772 & 0,807 & 0,822 & 0,800 & 0,813 & 0,811 & 0,823 \\
\hline
\end{tabular}

Table 1. Dependent variable is the unemployment rate $u_{t}$. Regressors are the mean and the standard deviation of CPI for all goods increments $\left(\triangle C P I \_m\right.$ and $\left.\triangle C P I_{\_} s t d\right)$, of GDP deflator increments $\left(\triangle D E F \_m\right.$ and $\left.\triangle D E F \_s t d\right)$, of nominal labor compensation increments $\left(\Delta N W_{-} m\right.$ and $\left.\Delta N W_{-} s t d\right)$, of gross value added employment ratio increments $\left(\Delta \operatorname{LabProd} \bar{d}_{-} m\right.$ and $\Delta$ LabProd_std). All specifications include intercepts and coefficients on time dummies that are not reported. $\mathrm{p}$-value $<0,01$ is defined as $* * *$, p-value $<0.05$ as ${ }^{* *}, \mathrm{p}<0.1$.is defined as $*$. 


\begin{tabular}{|c|c|c|c|c|}
\hline Regressors & (8) & (9) & (10) & (11) \\
\hline$\triangle$ CPI_m & & $-0,4732 \cdots \cdots$ & & \\
\hline t-statistics & & $-9,999$ & & \\
\hline$\Delta$ CPI_std & & $0, \mathbf{4 4 3 2} \div \div$ & & \\
\hline t-statistics & & 6,006 & & \\
\hline$\triangle \mathrm{DEF}$ m & & & $-0,396^{* \cdots *}$ & \\
\hline$t$-statistics & & & $-8,927$ & \\
\hline$\Delta \mathrm{DEF}$ std & & & $0,3602 \ldots$ & \\
\hline t-statistics & & & 4,713 & \\
\hline$\Delta \mathrm{NW}$ _m & & & & $-0,2976$ *** \\
\hline t-statistics & & & & $-5,316$ \\
\hline$\Delta N W$ Nstd & & & & $-0,2001 * * \pi$ \\
\hline t-statistics & & & & $-2,593$ \\
\hline$\Delta \mathrm{TFP} \_\mathrm{m}$ & $-0,0504$ & $-0,1826^{*}$ & $-0,1164$ & 0,0968 \\
\hline t-statistics & $-0,468$ & $-1,800$ & $-1,145$ & $-0,873$ \\
\hline$\Delta$ TFP_std & $0,6655 \div \div$ & $0,5206^{* \pi *}$ & $0,5664 \div \approx$ & $0,7582 \div ;=$ \\
\hline t-statistics & 5,022 & 4,005 & 4,350 & 0,873 \\
\hline Observations & 664 & 660 & 660 & 664 \\
\hline LSDV R-squared & 0,838 & 0,862 & 0,856 & 0,847 \\
\hline
\end{tabular}

Table 2. Dependent variable is the unemployment rate $u_{t}$. Regressors are the mean and the standard deviation of CPI for all goods increments $(\triangle C P I+m$ and $\left.\triangle C P I \_s t d\right)$, of GDP deflator increments $\left(\triangle D E F \_m\right.$ and $\left.\triangle D E F \_s t d\right)$, of nominal labor compensation increments $\left(\Delta N W_{-} m\right.$ and $\left.\Delta N W_{-} s t d\right)$, of total factor productivity increments $\left(\triangle T F P_{-} m\right.$ and $\left.\bar{\Delta} T F P_{-} s t d\right)$. All specifications include intercepts and coefficients on time dummies that are not reported. not shown. $\mathrm{p}$-value $<0,01$ is defined as $* * *$, $\mathrm{p}$-value $<0.05$ as $* *, \mathrm{p}<0.1$.is defined as $*$. 


\begin{tabular}{|c|c|c|c|c|}
\hline Regressors & $\begin{array}{c}\text { (12) up to } \\
1983\end{array}$ & $\begin{array}{c}\text { (13) after } \\
1983\end{array}$ & $\begin{array}{c}\text { (14) up to } \\
1983\end{array}$ & $\begin{array}{c}\text { (15) after } \\
1983\end{array}$ \\
\hline$\Delta$ CPI_m & 0,1041 & $-0,0841^{* \cdots *}$ & & \\
\hline$t$-statistics & 1,111 & $-6,211$ & & \\
\hline$\Delta$ CPI_std & $-0,1993$ & $0,0793 \div \div$ & & \\
\hline t-statistics & $-1,653$ & 2,395 & & \\
\hline$\triangle \mathrm{DEF}$ m & & & 0,0028 & $-0,0958 ; \cdots ;$ \\
\hline$t$-statistics & & & 0,026 & $-6,902$ \\
\hline$\Delta \mathrm{DEF} \_$std & & & 0,0848 & $0,0859 \div ;$ \\
\hline$t$-statistics & & & 0,565 & 2,183 \\
\hline$\Delta$ LabProd_m & $-0,0157$ & 0,1280 & $-0,1737$ & $0,1475^{*}$ \\
\hline$t$-statistics & $-0,076$ & 1,468 & $-0,743$ & 1,737 \\
\hline$\Delta$ LabProd_std & 0,1058 & $0,2283 * \pi$ & $-0,0276$ & 0,$2295 ; \cdots$ \\
\hline t-statistics & 0,423 & 3,116 & 0,096 & 3,216 \\
\hline Observations & 112 & 704 & 108 & 707 \\
\hline LSDV R-squared & 0,928 & 0,847 & 0,922 & 0,848 \\
\hline
\end{tabular}

Table 3. Dependent variable is the unemployment rate $u_{t}$. Regressors are the mean and the standard deviation of CPI for all goods increments $\left(\triangle C P I_{-} m\right.$ and $\left.\triangle C P I_{-} s t d\right)$, of GDP deflator increments $\left(\triangle D E F \_m\right.$ and $\left.\triangle D E F \_s t d\right)$, of gross value added -

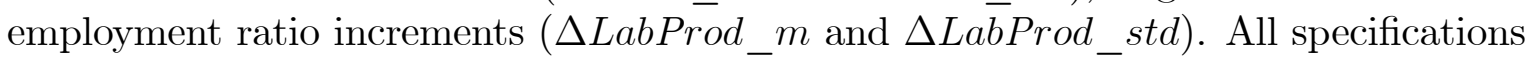
include intercepts and coefficients on time dummies that are not reported. not shown. $\mathrm{p}$-value $<0,01$ is defined as ${ }^{* * *}, \mathrm{p}$-value $<0.05$ as ${ }^{* *}, \mathrm{p}<0.1$.is defined as $*$. 


\begin{tabular}{|l|rrr|}
\hline \multicolumn{1}{|c|}{ Country } & \multicolumn{1}{c}{$\Delta \mathrm{CPI}$} & \multicolumn{1}{c|}{$\Delta \mathrm{DEF}$} & \multicolumn{1}{c|}{$\Delta \mathrm{NW}$} \\
\hline Australia & 5,82 & 5,91 & 7,74 \\
Austria & 3,66 & 3,40 & 5,99 \\
Belgium & 4,11 & 3,87 & 5,79 \\
Canada & 4,59 & 4,68 & 6,39 \\
Chile & 35,06 & 8,64 & 6,62 \\
Czech Rep. & 4,59 & 7,04 & 5,52 \\
Denmark & 5,18 & 5,36 & 6,42 \\
Estonia & 4,36 & 9,91 & 8,98 \\
Finland & 5,57 & 5,55 & 6,36 \\
France & 5,06 & 5,02 & 7,29 \\
Genmany & 2,99 & 2,70 & 5,61 \\
Greece & 11,03 & 11,33 & 7,03 \\
Hungary & 14,46 & 11,96 & 6,35 \\
Irland & 4,82 & 7,12 & 8,34 \\
Israel & 50,70 & 48,91 & 3,77 \\
Italy & 7,38 & 8,42 & 5,39 \\
Japan & 3,54 & 2,08 & 6,64 \\
South Korea & 9,00 & 9,93 & 12,42 \\
Luxembourg & 3,92 & 4,00 & 8,42 \\
Mexico & 30,77 & 30,06 & 6,53 \\
Netherlands & 3,86 & 3,50 & 6,30 \\
New Zealand & 6,96 & 7,13 & 5,72 \\
Norway & 5,34 & 5,52 & 7,45 \\
Poland & 15,79 & 13,10 & 5,72 \\
Portugal & 10,91 & 11,47 & 6,70 \\
Russia Fed. & 41,47 & 23,69 & $\mathbf{1 2 , 0 1}$ \\
Slovenia & 116,45 & 20,15 & 5,62 \\
Spain & 8,08 & 8,44 & 6,99 \\
Sweden & 5,39 & 5,53 & 5,62 \\
Switzerland & 3,05 & 2,71 & 5,87 \\
Turkey & 42,11 & 47,48 & 5,98 \\
United Kingdom & 6,22 & 6,60 & 6,70 \\
United States & 4,53 & 3,93 & 1,93 \\
\hline Median & 5,57 & 7,04 & 6,39 \\
Mean & 14,48 & 10,65 & 6,66 \\
\hline
\end{tabular}

Table 4. Columns show for each country the mean values calculated over 10-year rolling windows for CPI index inflation, gdp deflator index growth and nominal labor compensation growth respectively. Reference period is 1961-2011. Mean values above the cross-country median are in bold. 


\begin{tabular}{|c|c|c|c|c|c|}
\hline Regressors & $(16)$ & Regressors & (17) & Regressors & (18) \\
\hline $\begin{array}{l}\Delta \mathrm{CPI} \text { _m } \\
\text { t-statistics }\end{array}$ & $\begin{array}{c}-0,2034^{* * *} \\
-3,427\end{array}$ & $\begin{array}{l}\Delta \mathrm{DEF} \_\mathrm{m} \\
\text { t-statistics }\end{array}$ & 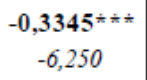 & $\begin{array}{l}\Delta \mathrm{NW} \text { _m } \\
\text { t-statistics }\end{array}$ & $\begin{array}{c}-\mathbf{0 , 3 3 9 4} \approx * * \\
-5,318\end{array}$ \\
\hline $\begin{array}{l}\Delta \text { CPI_std } \\
\text { t-statistics }\end{array}$ & $\begin{array}{c}\mathbf{0 , 4 9 3 0} \cdots * \pi \\
3,667\end{array}$ & $\begin{array}{l}\Delta \mathrm{DEF} \text { _std } \\
\text { t-statistics }\end{array}$ & $\begin{array}{c}\mathbf{0 , 4 0 1 2} \cdots *= \\
3,848\end{array}$ & $\begin{array}{l}\Delta \mathrm{NW} \text { _std } \\
\text { t-statistics }\end{array}$ & $\begin{array}{c}-0, \mathbf{3 0 2 1} \\
2,151\end{array}$ \\
\hline $\begin{array}{l}\Delta \text { LabProd_m } \\
\text { t-statistics }\end{array}$ & $\begin{array}{c}-0,4773 ; * * \\
-4,093\end{array}$ & $\begin{array}{l}\Delta \text { LabProd_m } \\
\text { t-statistics }\end{array}$ & $\begin{array}{c}-\mathbf{0}, \mathbf{3 4 5} 7 * * * \\
-2,849\end{array}$ & $\begin{array}{l}\Delta \text { LabProd_m } \\
\text { t-statistics }\end{array}$ & $\begin{array}{c}\mathbf{0 , 3 4 5 5} \\
2,333\end{array}$ \\
\hline $\begin{array}{l}\Delta \text { LabProd_std } \\
\text { t-statistics }\end{array}$ & $\begin{array}{c}-0,0474 \\
-0,426\end{array}$ & $\underset{t \text {-statistics }}{\Delta \text { LabProd_std }}$ & $\begin{array}{l}0,1570 \\
-1,474\end{array}$ & $\begin{array}{l}\Delta \text { LabProd_std } \\
\text { t-statistics }\end{array}$ & $\begin{array}{c}\mathbf{0 , 2 5 0 3} * * \\
2,344\end{array}$ \\
\hline $\begin{array}{l}\mathrm{d} \Delta \mathrm{CPI} \mathrm{m} \\
\text { t-statistics }\end{array}$ & $\begin{array}{c}0,1154 * * \\
-1,866\end{array}$ & $\begin{array}{l}\mathrm{d} \triangle \mathrm{DEF} \_\mathrm{m} \\
\text { t-statistics }\end{array}$ & $\begin{array}{c}0,2464 ; * \pi \\
4,714\end{array}$ & $\begin{array}{l}\mathrm{d} \Delta \mathrm{NW} \mathrm{W} \\
t \text {-statistics }\end{array}$ & 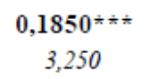 \\
\hline $\begin{array}{l}\text { d } \Delta \text { CPI_std } \\
\text { t-statistics }\end{array}$ & $\begin{array}{c}-0, \mathbf{4 2 4 9} ; * * * \\
-3,066\end{array}$ & $\begin{array}{l}\mathrm{d} \triangle \mathrm{DEF} \text { std } \\
\text { t-statistics }\end{array}$ & $\begin{array}{c}-0,3725 \text {; * * } \\
-3,285\end{array}$ & $\begin{array}{l}\mathrm{d} \Delta \mathrm{NW} \text { _std } \\
\text { t-statistics }\end{array}$ & $\begin{array}{c}0,1541 \\
0,491\end{array}$ \\
\hline $\begin{array}{l}\mathrm{d} \Delta \text { LabProd_m } \\
\text { t-statistics }\end{array}$ & $\begin{array}{c}\mathbf{0 , 4 0 7 0} \\
2,805\end{array}$ & $\underset{t \text {-statistics }}{\mathrm{d} \Delta \text { LabProd_m }}$ & $\begin{array}{l}0,2082 \\
1,402\end{array}$ & $\begin{array}{l}\mathrm{d} \Delta \text { LabProd_m } \\
\text { t-statistics }\end{array}$ & $\begin{array}{c}-0,7438 \cdots * \pi \\
-4,189\end{array}$ \\
\hline $\begin{array}{l}\mathrm{d} \Delta \text { LabProd_std } \\
\text { t-statistics }\end{array}$ & $\begin{array}{c}0,2383 \\
1,634\end{array}$ & $\begin{array}{l}\mathrm{d} \Delta \text { LabProd_std } \\
\text { t-statistics }\end{array}$ & $\begin{array}{l}-0,1065 \\
-0,744\end{array}$ & $\begin{array}{l}\mathrm{d} \Delta \text { LabProd_std } \\
\text { t-statistics }\end{array}$ & $\begin{array}{c}0,0892 \\
0,491\end{array}$ \\
\hline Observations & 816 & & 815 & & 765 \\
\hline LSDV R-squared & 0,817 & & 0,817 & & 0,830 \\
\hline
\end{tabular}

Table 5. Dependent variable is the unemployment rate $u_{t}$. Regressors are the mean and the standard deviation of CPI for all goods increments $\left(\triangle C P I \_m\right.$ and $\left.\triangle C P I \_s t d\right)$, of GDP deflator increments $\left(\triangle D E F \_m\right.$ and $\left.\triangle D E F \_s t d\right)$, of nominal labor compensation increments $\left(\Delta N W \_m\right.$ and $\left.\Delta N W \_s t d\right)$, of gross value added employment ratio increments $(\Delta$ LabProd_m and $\Delta$ LabProd_std). The product terms between previous regressors and inflation dummies are $d \Delta C P I \_m$ and $d \Delta C P I \_s t d$ for CPI increments dummy, $d \Delta D E F \_m$ and $d \Delta D E F \_s t \bar{d}$ for GDP deflator increments dummy, $d \Delta N W \_m$ and $d \Delta N \bar{W} \_s t d$ for labor compensation increments dummy. The terms $d \Delta L a b \bar{P} r o d \_m$ and $d \Delta \bar{L} a b P r o d \_s t d$, which relate the labor productivity to the inflation dummy, change according to the measure of inflation considered. All specifications include intercepts and coefficients on time dummies that are not reported. not shown. $\mathrm{p}$-value $<0,01$ is defined as $* * *$, $\mathrm{p}$-value $<0.05$ as ${ }^{* *}, \mathrm{p}<0.1$.is defined as * 